DOI: $10.1002 /$ ((please add manuscript number))

Article type: Full Paper

\title{
Impact of monovalent cation halide additives on the structural and optoelectronic properties of $\mathrm{CH}_{3} \mathrm{NH}_{3} \mathrm{PbI}_{3}$ perovskite
}

Mojtaba Abdi-Jalebi, M. Ibrahim Dar,* Aditya Sadhanala, Satyaprasad P. Senanayak, Marius Franckevičius, Neha Arora, Yuanyuan Hu, Mohammad Khaja Nazeeruddin, Shaik M. Zakeeruddin, Michael Grätzel, * Richard H. Friend*

M Abdi-Jalebi, Dr. Aditya Sadhanala, Dr. S. P. Senanayak, Dr. Y. Hu, Prof. R. H. Friend Cavendish Laboratory, Department of Physics, University of Cambridge, JJ Thomson Avenue, Cambridge CB3 OHE, UK

E-mail: rhf10@cam.ac.uk; ibrahim.dar@epfl.ch; michael.graetzel@epfl.ch

Dr. M. I. Dar, Dr. N. Arora, Dr. S. M. Zakeeruddin, Prof. M. Grätzel

Laboratory of Photonics and Interfaces, Institute of Chemical Sciences and Engineering, École Polytechnique Fédérale de Lausanne, CH-1015 Lausanne, Switzerland

Dr. M. Franckevičius,

Center for Physical Sciences and Technology, Savanorių Ave. 231, LT-02300 Vilnius, Lithuania

Prof. M. K. Nazeeruddin

Group for Molecular Engineering of Functional Materials, Institute of Chemical Sciences and Engineering, École Polytechnique Fédérale de Lausanne, CH-1015-Lausanne, Switzerland 


\begin{abstract}
We report the influence of monovalent cation halide additives on the optical, excitonic and electrical properties of $\mathrm{CH}_{3} \mathrm{NH}_{3} \mathrm{PbI}_{3}$ perovskite. Monovalent cation halide with similar ionic radii to $\mathrm{Pb}^{2+}$, including $\mathrm{Cu}^{+}, \mathrm{Na}^{+}$and $\mathrm{Ag}^{+}$, were added to explore possibility of doping. We observed significant reduction of subbandgap optical absorption and lower energetic disorder along with a shift in the Fermi level of the perovskite in the presence of these cations. The bulk hole mobility of the additive based perovskites as estimated using the space charge limited current method exhibited an increase of up to an order of magnitude compared to the pristine perovskites with a significant decrease in the activation energy. Consequentially, enhancement in the photovoltaic parameters of additive-based solar cells was achieved. We observed an increase in open circuit voltage for $\mathrm{AgI}(\sim 1.02$ vs $0.95 \mathrm{~V}$ for the pristine $)$ and photocurrent density for $\mathrm{NaI}$ and $\mathrm{CuBr}$ based solar cells $\left(\approx 23 \mathrm{vs} 21 \mathrm{~mA} \cdot \mathrm{cm}^{-2}\right.$ for the pristine). This enhanced photovoltaic performance could be attributed to the formation of uniform and continuous perovskite film, better conversion and loading of perovskite as well as the enhancement in the bulk charge transport along with a minimization of disorder, pointing towards possible surface passivation.
\end{abstract}

Keywords: Monovalent cation halide, additives, $\mathrm{CH}_{3} \mathrm{NH}_{3} \mathrm{PbI}_{3}$ Perovskite, doping, surface passivation 


\section{Introduction}

Nowadays, organic-inorganic metal halide perovskites have been receiving tremendous attention owing to their facile synthesis ${ }^{[1]}$, low temperature deposition ${ }^{[2]}$, capability to make flexible devices $^{[3]}$, and extraordinary optical and electronic properties ${ }^{[4,5]}$. Organic-inorganic metal halide perovskites have a cubic framework structure with general formula $\mathrm{ABX}_{3}$ (where $\mathrm{A}$ is an organic cation, $\mathrm{B}$ a divalent metal ion and $\mathrm{X}$ a halide ion $\mathrm{Cl}, \mathrm{Br}$ or $\mathrm{I}$ or any mixture thereof). Perovskitesensitized solar cell employing a liquid electrolyte was first documented by Miyasaka and coworkers, and reported an efficiency of $3.8 \%$ for $\mathrm{CH}_{3} \mathrm{NH}_{3} \mathrm{PbI}_{3}$ based solar cell ${ }^{[1]}$. In recent years, perovskite solar cells (PSC) have shown a paradigm shift in photovoltaic technology, mainly by adopting device configuration ranging from mesoscopic semiconducting $\mathrm{TiO}_{2}^{[6,7]}$ or insulating $\mathrm{Al}_{2} \mathrm{O}_{3}$ scaffolds ${ }^{[8]}$, to the planar heterojunction $(\mathrm{PHJ})$ architecture ${ }^{[3,9]}$. Recently, a certified power conversion efficiency of over $20 \%^{[10]}$ has been reported through optimizing device design, material interfaces, processing techniques and chemical composition of perovskite materials ${ }^{[11-13]}$. These recent developments further demonstrate the promising potential of PSC to compete with silicon solar cells in the photovoltaic markets ${ }^{[14]}$.

In general, there are four methods, which includes one step spin deposition ${ }^{[15]}$, vacuum vapor deposition $^{[9]}$, two-step deposition technique ${ }^{[6,16]}$, and patterning thin film ${ }^{[17]}$ to prepare the hybrid organic-inorganic perovskite film. So far, solution processed PSC show the highest efficiency and stability ${ }^{[12,18]}$. However, achieving good quality solution processed $\mathrm{CH}_{3} \mathrm{NH}_{3} \mathrm{PbI}_{3}$ films on top of mesoporous $\mathrm{TiO}_{2}\left(\mathrm{~ms}-\mathrm{TiO}_{2}\right)$ with high uniformity and smoothness is a challenge. In many PSC, a non-continuous perovskite film is usually obtained, where pinholes can introduce shunting pathways limiting the device performance. Recent studies show that by upon addition of excess organic component (methyl ammonium iodide) much larger crystalline domains can be created ${ }^{[8]}$, and smoother films can be formed than those processed from a stoichiometric mixture of $\mathrm{CH}_{3} \mathrm{NH}_{3} \mathrm{I}$ and $\mathrm{PbI}_{2}{ }^{[19]}$. In addition, it is found that changing the anions from halide to acetate in 
the lead source of perovskite solution has an effective influence on the perovskite crystal growth and therefore improves the film quality ${ }^{[20]}$. On the other hand, hybrid $\mathrm{CH}_{3} \mathrm{NH}_{3} \mathrm{PbI}_{3}$ doped with $\mathrm{Sn}^{2+}, \mathrm{Sr}^{2+}, \mathrm{Cd}^{2+}$ and $\mathrm{Ca}^{2+}$ in the position of the $\mathrm{Pb}^{2+}$ ion, are also known to affect both the crystalline phase and the band gap energy ${ }^{[21]}$. A complete understanding of these issues is hence critically important for advancing our understanding of perovskite semiconductors and solar cell performance.

Despite the rapid rise in the PSC performance, the fundamental properties of organic-inorganic trihalide perovskites pertaining to the formation of perovskite are not yet well understood. Various investigations have focused on tuning the band gap of absorber material by changing the ratio of cations ${ }^{[22]}$, anions ${ }^{[5]}$ or the divalent metal ${ }^{[23,24]}$. But, the effect of precursor composition on the perovskite crystal growth, film formation, coverage and thus on the device performance, is yet to be investigated in detail ${ }^{[20,25,26]}$.

In this work, we explore the effect of adding small amount of monovalent cation halide based salts including $\mathrm{NaI}, \mathrm{CuBr}, \mathrm{CuI}$ and $\mathrm{AgI}$ into the perovskite precursor solution on morphology, charge transport, excitonic and optical properties of $\mathrm{CH}_{3} \mathrm{NH}_{3} \mathrm{PbI}_{3}$ perovskite. To the best of our knowledge, the incorporation of $\mathrm{CH}_{3} \mathrm{NH}_{3} \mathrm{PbI}_{3}$ with aforementioned salts has not been reported so far. Morphological characterization based on field emission scanning electron microscopy (FESEM) determined that shape and coverage of the $\mathrm{CH}_{3} \mathrm{NH}_{3} \mathrm{PbI}_{3}$ structures prepared in the presence of additives is considerably different from an additive-free reference. In addition, samples were characterized using X-ray diffraction (XRD) to study crystalline phases present in the samples and the extent of lead halide conversion into perovskite in presence of additives. Comprehensive studies on optical properties of additive based perovskite were carried out using photothermal deflection spectroscopy (PDS), UV-visible absorption and photoluminescence (PL). In addition, kelvin probe force microscopy (KPFM) and space charge limited current (SCLC) technique were used to characterise influence of aforementioned additives on electrical properties of $\mathrm{CH}_{3} \mathrm{NH}_{3} \mathrm{PbI}_{3}$ 
perovskite. Finally, fabrication of solar cells based on the incorporated monovalent cation in perovskite structure reveals an improvement in power conversion efficiency (PCE) reaching $15.6 \%$ which can be ascribed to the improvement in the conversion reaction, optical, excitonic and electrical properties of $\mathrm{CH}_{3} \mathrm{NH}_{3} \mathrm{PbI}_{3}$.

\section{Results and discussion}

In this study, $\mathrm{CH}_{3} \mathrm{NH}_{3} \mathrm{PbI}_{3}$ perovskite samples were synthesized using sequential two-steps deposition process $^{[6]}$ in which 0.02 mol. $\mathrm{L}^{-1}$ of different additives including $\mathrm{NaI}, \mathrm{CuBr}, \mathrm{CuI}$ and $\mathrm{AgI}$ were added into the 1.2 mol.L $\mathrm{L}^{-1} \mathrm{PbI}_{2}$ solution in $\mathrm{N}, \mathrm{N}$-dimethylformamide (DMF). In this procedure, the $\mathrm{CH}_{3} \mathrm{NH}_{3} \mathrm{PbI}_{3}$ is formed onto $\sim 250 \mathrm{~nm}$ thick $\mathrm{TiO}_{2}$ photoanode films by spin coating DMF solution of $\mathrm{PbI}_{2}$ followed by dip coating in a solution of isopropyl alcohol containing methylamonium iodide (MAI) under optimized conditions.

\subsection{Morphological characterization}

To understand the impact of these additives on the surface morphology of the $\mathrm{PbI}_{2}$ and $\mathrm{CH}_{3} \mathrm{NH}_{3} \mathrm{PbI}_{3}$ deposited on mesoporous $\mathrm{TiO}_{2}$ photoanode, field emission scanning electron microscopy (FESEM) was employed. The top view SEM image confirms that the mesoporous $\mathrm{TiO}_{2}$ is covered by an overlayer of $\mathrm{PbI}_{2}$ (Figure 1, left-side). It is noteworthy that a significant change in the morphology of $\mathrm{PbI}_{2}$ overlayer is observed while adding $\mathrm{NaI}$ to its solution (Figure 1d) and a rough and highly porous overlayer of $\mathrm{PbI}_{2}$ containing branched large crystals was formed. This morphological difference was also evident from the macroscopic image (Figure S1a) as the respective $\mathrm{PbI}_{2}$ film including $\mathrm{NaI}$ is relatively more scattering compared to pristine lead iodide film (Figure S1b).

In addition, the presence of $\mathrm{CuBr}$ does not make any significant difference in the morphology of $\mathrm{PbI}_{2}$ (Figure 1b) whereas, in case of $\mathrm{CuI}$ and $\mathrm{AgI}$ based samples, we, obtain a uniform and pinhole free overlayer (Figure 1c, e). The right side of Figure 1 displays top-view SEM images of $\mathrm{CH}_{3} \mathrm{NH}_{3} \mathrm{PbI}_{3}$ films obtained after the conversion of pristine and additive based $\mathrm{PbI}_{2}$ films. 
Comparative SEM analysis brought out variations in perovskite morphology. Pristine samples revealed the formation of large tetragonal-shaped perovskite crystals on top of the $\mathrm{ms}^{-} \mathrm{TiO}_{2}$ film while relatively better surface coverage of mesoporous- $\mathrm{TiO}_{2}$ with perovskite crystal is observed for $\mathrm{CuBr}$ based sample (Figure 1b). Moreover, considerable improvement in the surface coverage of titania scaffold with uniform and continuous perovskite structure is observed in the presence of $\mathrm{CuI}$ and $\mathrm{AgI}$ additives (Figure 1c, e). Particularly, in the case of $\mathrm{CH}_{3} \mathrm{NH}_{3} \mathrm{PbI}_{3}$ incorporated with AgI, the perovskite crystals are better-connected. In Figure 2d, large crystals of NaI based perovskite sample with asymmetric shape are observed which infers that the nature of $\mathrm{PbI}_{2}$ film can define the morphological properties of resulting perovskite films.

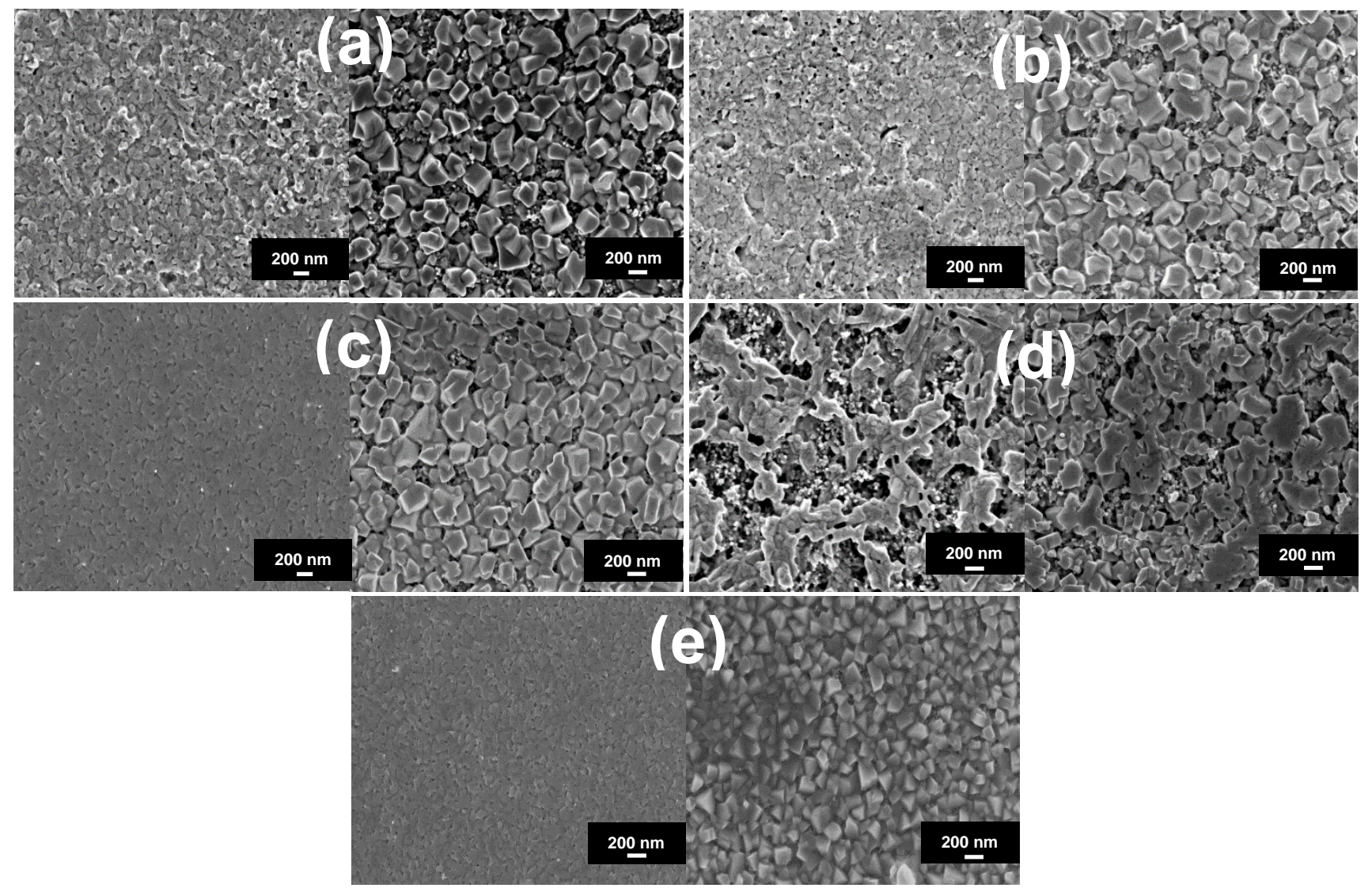

Figure 1. Top-view SEM images of $\mathrm{PbI}_{2}$ (left side) and $\mathrm{CH}_{3} \mathrm{NH}_{3} \mathrm{PbI}_{3}$ (right side) structures: (a) pristine, (b) CuBr-, (c) CuI-, (d) NaI- and (e) AgI-based perovskite samples deposited on a mesoporous $\mathrm{TiO}_{2}$-coated FTO. 
We further characterized the perovskite films obtained from pristine and additives based lead halide precursors by atomic force microscopy (AFM) (Figure 2). The root mean-squared roughness of the pristine, $\mathrm{CuBr}, \mathrm{CuI}, \mathrm{NaI}$, and $\mathrm{AgI}$ based perovskite films was found to be 51.2, 28.2, 21.3, 63.0 and $17.7 \mathrm{~nm}$, respectively. Expectedly, perovskite film including NaI additive exhibits a branched morphology with the highest roughness whereas the roughness of CuI and
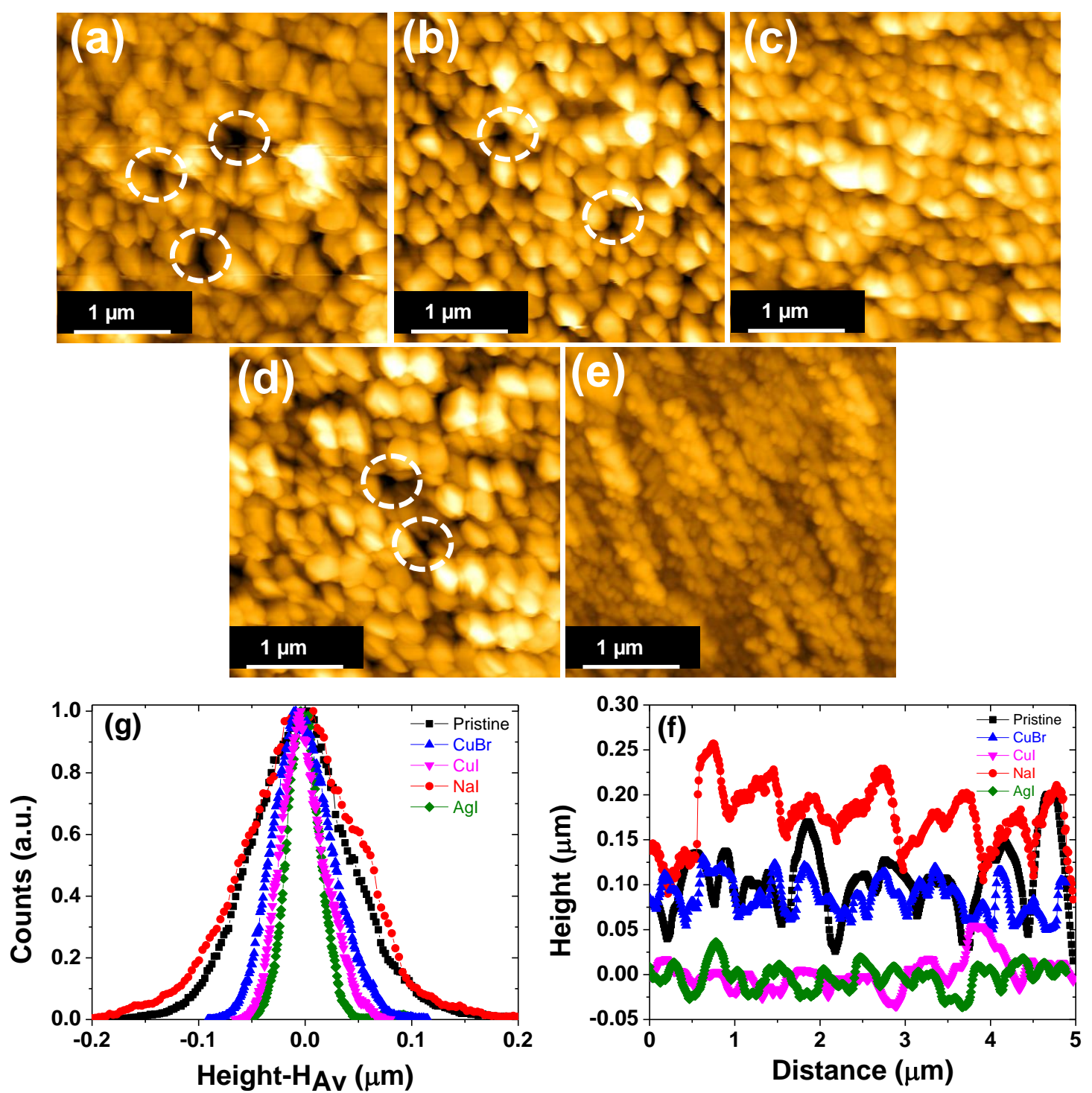

Figure 2. AFM images of perovskite structures: (a) pristine, (b) $\mathrm{CuBr}^{-}$, (c) CuI-, (d) NaI- and (e) AgI-based $\mathrm{CH}_{3} \mathrm{NH}_{3} \mathrm{PbI}_{3}$ deposited on a mesoporous $\mathrm{TiO}_{2}$-coated FTO. Examples of pinholes in pristine, $\mathrm{CuBr}$ and $\mathrm{NaI}$ derived films are circled, which are notably absent in the $\mathrm{CuI}$ and $\mathrm{AgI}$ based films. Line segments from each scan (f) and the height distribution ( $g$ ) around the average height, $\mathrm{H}_{\mathrm{Av}}$, show the exceptional smoothness of the AgI and CuI-derived films. 
AgI based films are greatly reduced compared with the pristine sample, as is evident from both, AFM line segments (Figure 2f) and height distribution analysis (Figure 2g). It is worth emphasizing that the perovskite films including $\mathrm{CuI}$ and $\mathrm{AgI}$ additives are nearly pinhole free as compared to pristine and other samples (see circles in Figure 2a, b and d). It is encouraging that by adding small amount of additives inside the lead halide precursor solution, the smoothness of the perovskite films prepared by two-step deposition method enhanced strongly.

\subsection{Structural characterization}

To investigate the effect of monovalent cation halide additives on the crystal structure of $\mathrm{PbI}_{2}$ and $\mathrm{CH}_{3} \mathrm{NH}_{3} \mathrm{PbI}_{3}$ perovskite, $\mathrm{X}$-ray diffraction spectroscopy was carried out. In Figure 3, we show the $\mathrm{X}$-ray diffraction patterns of pristine- and additive based- $\mathrm{PbI}_{2}$ and $-\mathrm{CH}_{3} \mathrm{NH}_{3} \mathrm{PbI}_{3}$ films, respectively. These diffraction patterns are indexed based on the standard JCPD file number 01072-1147 and 21-1272 for FTO and $\mathrm{TiO}_{2}$, respectively, as well as using literature data for $\mathrm{PbI}_{2}$ and $\mathrm{CH}_{3} \mathrm{NH}_{3} \mathrm{PbI}_{3}$ perovskite ${ }^{[27]}$.

According to the literature data, it is evident that the $\mathrm{PbI}_{2}$ deposited by spin-coating from $\mathrm{DMF}$ solution crystallizes in the form of the hexagonal $2 \mathrm{H}$ polytype ${ }^{[28]}$. The presence of the most intense diffraction peak $(2 \theta=12.60)$ indexable to the (001) lattice planes (Figure 3a, black curve), is indicative of preferential growth of $\mathrm{PbI}_{2}$ crystallites along the c-axis.

It should be noted that $\mathrm{CuBr}, \mathrm{CuI}$ and $\mathrm{AgI}$-based perovskite films show similar intensity in various diffraction peaks to the pristine one, however the NaI-based sample depicts sharper diffraction peaks for the (001) lattice plane. Moreover, sharpness of the diffraction peak (001) for NaI based sample compare to broad one for the pristine can be attributed to the larger crystallite size of $\mathrm{PbI}_{2}$ structures which demonstrates that $\mathrm{NaI}$ additive influences the growth of $\mathrm{PbI}_{2}$ structures (Figure 1d).

The conversion of $\mathrm{PbI}_{2}$ into $\mathrm{CH}_{3} \mathrm{NH}_{3} \mathrm{I}$ was ascertained by X-ray diffraction (XRD). All the 

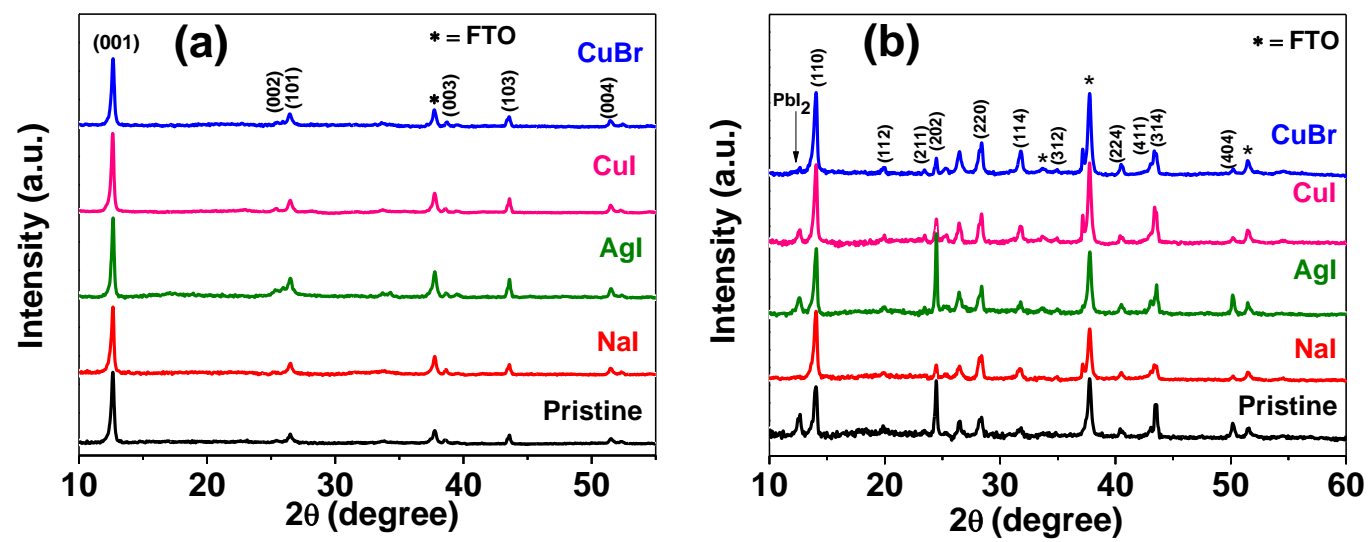

Figure 3. $\mathrm{X}$-ray diffraction spectra of pristine and additives based (a) $\mathrm{PbI}_{2}$ and (b) $\mathrm{CH}_{3} \mathrm{NH}_{3} \mathrm{PbI}_{3}$ perovskite that is grown on mesoporous $\mathrm{TiO}_{2}$ film which is deposited on the FTO coated glass.

diffraction peaks present in the XRD patterns could be indexed to the tetragonal phase of the $\mathrm{CH}_{3} \mathrm{NH}_{3} \mathrm{PbI}_{3}$ perovskite ${ }^{[29]}$. In addition, presence of diffraction peak $(2 \theta=12.6)$ attributable to $\mathrm{PbI}_{2}$ indicates the presence of unconverted $\mathrm{PbI}_{2}$ within the $\mathrm{CH}_{3} \mathrm{NH}_{3} \mathrm{PbI}_{3}$ film. XRD patterns obtained from the additives based samples perfectly match with that of pristine $\mathrm{CH}_{3} \mathrm{NH}_{3} \mathrm{PbI}_{3}$ sample which confirms that the presence of additives do not alter the crystal structure of the final $\mathrm{CH}_{3} \mathrm{NH}_{3} \mathrm{PbI}_{3}$ material (Figure 3b). However, based on an analysis using the Scherrer equation, ${ }^{[30]}$ the average crystallite sizes of pristine, $\mathrm{CuBr}, \mathrm{CuI}, \mathrm{NaI}$ and $\mathrm{AgI}$ based perovskite vary and were estimated to be $62 \pm 10,73 \pm 12,56 \pm 9,95 \pm 14$ and $45 \pm 11 \mathrm{~nm}$, respectively. It is important to note that these values are based on the assumption of spherical perovskite crystals.

In addition, it was also observed that the diffraction peak of $\mathrm{PbI}_{2}$ in $\mathrm{NaI}$-based sample vanished and its intensity dropped significantly in CuBr-based one. This observation can be attributed to the following two reasons; first, presence of additive is enhancing the extent of conversion reaction of $\mathrm{PbI}_{2}$ into $\mathrm{CH}_{3} \mathrm{NH}_{3} \mathrm{PbI}_{3}$ which eventually leaves less amount of unreacted $\mathrm{PbI}_{2}$. Secondly, morphological modifications of $\mathrm{PbI}_{2}$ overlayer, i.e., from a relatively compact layer to a more porous one, facilitates the conversion further. As the NaI-based sample reveals a full conversion of $\mathrm{PbI}_{2}$ into the $\mathrm{CH}_{3} \mathrm{NH}_{3} \mathrm{PbI}_{3}$, which has been already established from the XRD 
pattern, the second hypothesis seems more feasible. It is to be noted that significant variations in the morphology of $\mathrm{PbI}_{2}$ overlayer were observed in SEM analysis (Figure 1). On the other hand, a relatively high intense $\mathrm{PbI}_{2}$ diffraction peak is observed in the XRD patterns of $\mathrm{CuI}$ and $\mathrm{AgI}$ based samples. This further confirms that the morphology of $\mathrm{PbI}_{2}$ overlayer strongly influences the extent of $\mathrm{PbI}_{2}$ conversion into $\mathrm{CH}_{3} \mathrm{NH}_{3} \mathrm{PbI}_{3}$.

\subsection{Optical spectroscopy}

\subsubsection{UV-visible Absorption}

Steady state optical absorption and PL spectra of pristine and additives based methylammonium lead iodide perovskite films, are presented in Figure 4a. The optical absorption spectrum of pristine $\mathrm{CH}_{3} \mathrm{NH}_{3} \mathrm{PbI}_{3}$ perovskite film (solid black line) shows broad absorption band covering the entire visible spectral range with a band edge at around $780 \mathrm{~nm}$. Large extinction coefficient and typical spectral behaviour of methylammonium lead iodide perovskite film is consistent with the previous reports $^{[31]}$. The comparative analysis of absorption spectra of pristine and additives based $\mathrm{CH}_{3} \mathrm{NH}_{3} \mathrm{PbI}_{3}$ films do not show any noticeable position alterations i.e. the absorption onsets at $780 \mathrm{~nm}$ are very similar nevertheless, we observed a slight deviation in the absorption slopes which are below the band edge. Such deviations (without base line correction) could appear from strong light scattering, which originates from rough perovskite surface, rather than from the effect of additives. However, in order to verify whether presence of additive have any influence on the band gap position, we evaluated approximate band gap positions from the measured spectra. By performing scattering subtraction which is proportional to $\lambda^{-4}$ and by applying extrapolation to the linear part of absorption edge, we obtained that optical band gap of all synthesized films to be around $1.58 \mathrm{eV}$, which is in agreement with literature ${ }^{[32]}$. It should be noted that due to a very high perovskite layer thickness, which is $\approx 300 \mathrm{~nm}$, absorption spectrum below $600 \mathrm{~nm}$ becomes saturated and therefore precise interpretation of the results in this region becomes difficult. 

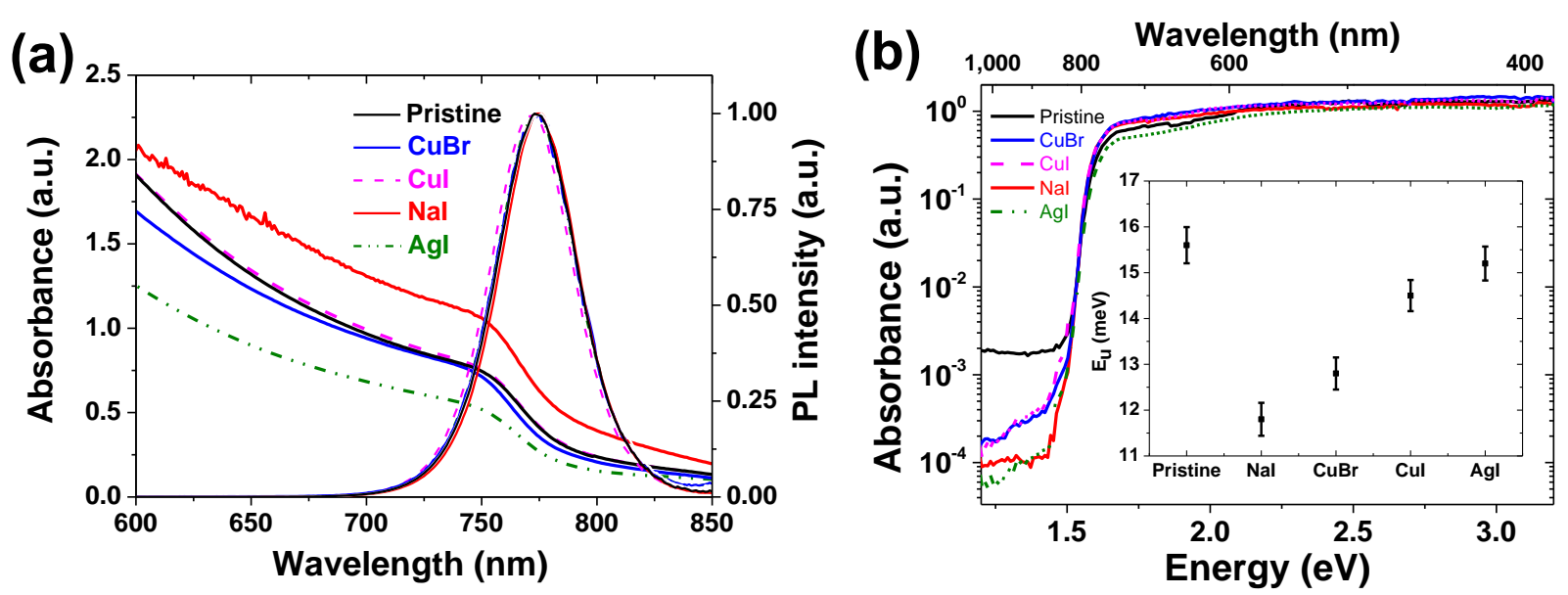

Figure 4. (a) Steady state absorption and PL spectra for pristine and additives based perovskite films. (b) The absorption spectra of perovskite films derived from pristine and additive based lead sources measured using the PDS technique. The inset shows the corresponding Urbach energies for all samples. The error bar is defined by the s.d in fitting the Urbach tail.

\subsubsection{Photoluminescence study}

Steady state PL spectra of perovskite films are presented in Figure 4a. Strong and narrow fluorescence bands with full-width half maximum of about $40 \mathrm{~nm}$ appear at around $775 \mathrm{~nm}$ upon sample excitation at $460 \mathrm{~nm}$. It is observed that the PL spectra are similar for all $\mathrm{CH}_{3} \mathrm{NH}_{3} \mathrm{PbI}_{3}$ films, i.e. pristine and additives based, confirming that the additives did not affect band edge of organo-metal perovskite semiconductors. This could be due to the tendency of additives to be at the crystalline surfaces rather than having impact on the band gap of perovskite films. Most likely, the effect of additives on the perovskite crystallization is more pronounced and influences film morphology which, can affect the photovoltaic performances ${ }^{[16]}$. PL decay measurements were performed using time-correlated single photon counting technique (see details in Figure S2). The estimated PL lifetimes and their relative contributions are summarized in Table S1. It is evident that PL decay kinetics experience several important differences depending on the type of additive. 


\subsection{Photothermal deflection spectroscopy (PDS)}

We used photothermal deflection spectroscopy (PDS), which is an ultrasensitive absorption measurement technique, to explore the optical absorption of the $\mathrm{CH}_{3} \mathrm{NH}_{3} \mathrm{PbI}_{3}$ films near the band edge (Figure 4b). PDS has a dynamic sensitivity range of 4-5 orders of magnitude and is less affected by optical light scattering. From Figure $4 b$, it is evident that the pristine perovskite has the highest sub-bandgap absorption. In addition, both copper based perovskite (e.g. CuI and $\mathrm{CuBr}$ ) samples shows relatively higher absorption compared to the $\mathrm{AgI}$ and $\mathrm{NaI}$ based perovskite films in the sub-bandgap region. It is notable that $\mathrm{Cu}$ based additives create a tail in the absorption spectra of perovskite which confirm the presence of these monovalent cations inside the film. In contrast to AgI and NaI, copper based additives absorb intrinsically (Figure S3) which generate aforementioned tail. Comparing the PDS absorption spectra for $\mathrm{CuBr}$ based $\mathrm{PbI}_{2}$ and perovskite shows that these additives are not fully incorporated in the perovskite film.

As reported by Sadhanala et al. for $\mathrm{CH}_{3} \mathrm{NH}_{3} \mathrm{PbI}_{3}$, we observe sharp band edges for all the samples with an exponential decay of the density of states after the band edge, known as the Urbach tail $^{[31,33]}$. The extent of the absorption tail below the band gap is correlated with the degree of electronic disorder within the material, which could originate from structural disorder, thermal fluctuation of the ions comprising the material and defects in the crystalline structure. Indeed, there have been several recent reports which suggest that the presence of defects within $\mathrm{CH}_{3} \mathrm{NH}_{3} \mathrm{PbI}_{3}$ perovskite crystals would induce localized states in the range of a few hundred meV from the extended states of the bands, which could result in the broadening of the Urbach tail ${ }^{[34]}$. Assuming the same level of thermal disorder, the slope of the exponential part of the Urbach tail

gives an estimation of the defect density, in terms of Urbach energy ' $E_{u}{ }^{,[31,33]}$. The estimated Urbach energies for the pristine and additive based perovskite samples are shown in the inset of Figure $4 b$, along with the respective fitting error, which are 15.6, 11.8, 12.8, 13.5 and $15.2 \mathrm{meV}$ for pristine, $\mathrm{NaI}, \mathrm{CuBr}, \mathrm{CuI}$ and $\mathrm{AgI}$ based perovskite, respectively. The data fittings are shown in 
the Figure S4. These values suggest that within the measurement error, additive based perovskite, particularly $\mathrm{NaI}, \mathrm{CuBr}$ and $\mathrm{CuI}$, have a lower level of electronic disorder compared to the pristine perovskites.

\subsection{Kelvin probe force microscopy (KPFM)}

We then used Kelvin probe force microscopy (KPFM), an electrical operation mode of scanning force microscopy (SFM), to investigate the effect of adding monovalent cation halide on $\mathrm{CH}_{3} \mathrm{NH}_{3} \mathrm{PbI}_{3}$ perovskite Fermi level. KPFM is a powerful technique based on measuring and compensating the electrostatic forces between a sample and an AFM tip to determine the local contact potential difference $(\mathrm{CPD})^{[35,36]}$, which is a measure of the Fermi level energy if the electron affinity is known. Previously, it has been used to study the electrical potential distribution across the internal interfaces of inorganic solar cells ${ }^{[37,38]}$. KPFM was recently used to characterize the perovskite top layer ${ }^{[39,40]}$, where the presence of a small potential barrier at the grain boundaries was found. Bergmann et al. have recently measured cross-sections of a complete perovskite based solar cell under illumination with KPFM and showed that the potential is similar to a p-i-n type junction ${ }^{[41]}$. Figure 5 shows CPD of line profiles recorded at pristine and additive based perovskite films which is sensitive to the surface work functions $\Phi$ of the materials. The line scan is carried out at the interface of perovskite and gold layer as shown in topography AFM image (Figure 5). Assuming that the tip work function remains constant during a line scan, the CPD reflects the built-in potential of the device. It is notable that adsorbed water on the surface may have altered the absolute value of the CPD, but not the relative difference between the studied materials.

We found a decreasing CPD from the pristine perovskite $(0.3 \mathrm{~V})$ towards the Au electrode $(\approx 0 \mathrm{~V}$, black line profile in in Figure 5). The difference between these two values corresponds to the differences of the work function of perovskite $\left(\Phi_{\text {perovskite }} / \mathrm{e} \approx 4.8 \mathrm{~V}\right)$ and $\mathrm{Au}\left(\Phi_{\mathrm{Au}} / \mathrm{e} \approx 5.1 \mathrm{~V}\right)$ which 


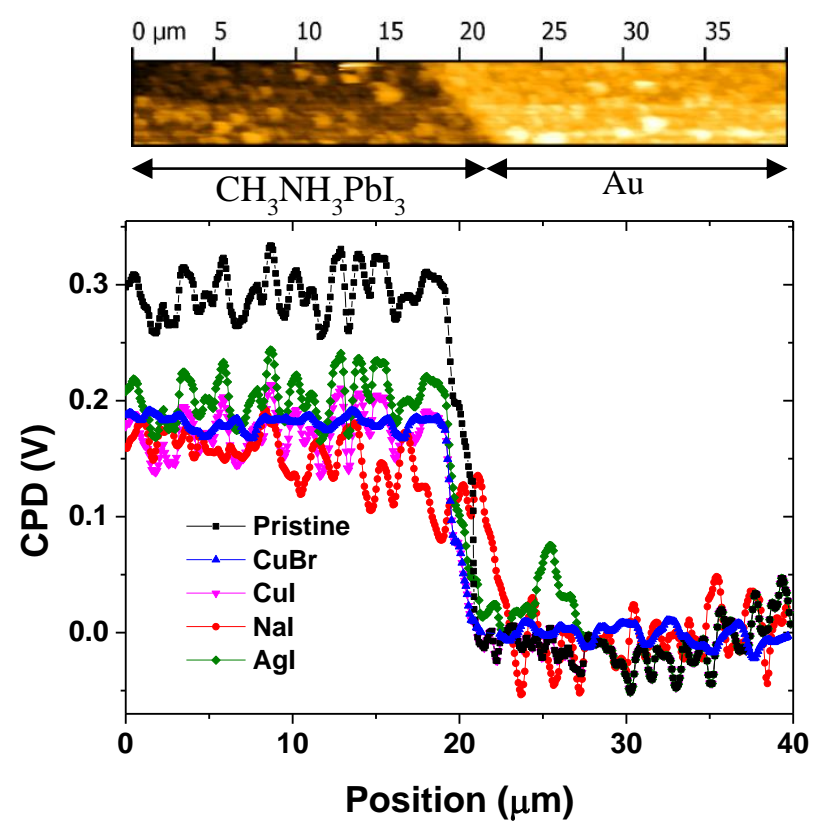

Figure 5. CPD line profiles recorded from pristine and additive based perovskite films using KPFM. The AFM topography image is shown on the top.

are comparable to the previous reports ${ }^{[41,42]}$. Surprisingly, the work function of additive based perovskite shifted significantly (about $0.1 \mathrm{~V}$ ) toward the Au work function. This shift in the work function can be attributed to the following two reasons; first, substitutional doping of perovskite in which $\mathrm{Pb}^{2+}$ is replaced by $\mathrm{Cu}^{+}, \mathrm{Na}^{+}$and $\mathrm{Ag}^{+}$cations resulting in generation of valance band holes. Thus, the Fermi level of the bulk perovskite thin film comes closer to the valence band. Secondly, these additives can potentially passivate the surface of perovskite film (where there is a missing iodide) and as a result reduce the contact potential difference which is measured by KPFM. It is notable that the chance of substitutional doping at the room temperature is very low since the excess energy associate with putting these monovalent cation (e.g. $\mathrm{Ag}^{+}$) in place of $\mathrm{Pb}^{2+}$ is very high ${ }^{[43]}$. Thus, the second scenario is more probable in which the crystalline surfaces of $\mathrm{CH}_{3} \mathrm{NH}_{3} \mathrm{PbI}_{3}$ are passivated in the presence of these monovalent cations.

\subsection{Charge transport measurement}


To further understand the role of the monovalent cations on the properties of the perovskite material, extensive charge transport measurements were performed. Both electron and hole only devices were fabricated (see details in Experimental section) with all the different perovskite materials to estimate the bulk carrier mobility $\left(\mu_{\mathrm{SCL}}\right)$. A clear transition from the linear to space charge limited trap free behavior is observed in all the materials (Figure 6a). The onset voltage of the trap-free space charge limited (TFSCL) transport regime is directly related to the density of trap states at the transport level ${ }^{[44]}$. In general, all the perovskite devices with typical thickness in the range of $0.5-1 \mu \mathrm{m}$ demonstrated TFSCL in a voltage range of $<5 \mathrm{~V}$, indicating low trap density. Child's law given by: $J=\frac{9}{8} \varepsilon_{0} \epsilon_{r} \mu_{S C L} \frac{V^{2}}{d^{3}}$ where, $\mathrm{J}$ is the current density, $\varepsilon_{\mathrm{o}}$ is the vacuum permittivity, $\varepsilon_{\mathrm{r}}$ is the dielectric constant of the active material which is measured to be in the range of $15-25$ (at $1 \mathrm{kHz}$ ) for different materials and $\mathrm{d}$ is the thickness of the active layer was utilized to estimate the bulk mobility of electrons and holes in the TFSCL regime ${ }^{[45]}$.

Typical electron mobility $\left(\mu_{S C L}^{e}\right)$ of $0.02 \mathrm{~cm}^{2} \cdot \mathrm{V}^{-1} \cdot \mathrm{s}^{-1}$ and hole mobility $\left(\mu_{S C L}^{h}\right)$ of $0.008 \mathrm{~cm}^{2} \cdot \mathrm{V}^{-1} \cdot \mathrm{s}^{-1}$ was obtained for pristine perovskite films. This magnitude of bulk mobility is lower than that reported for a single crystal of perovskite ${ }^{[44]}$. It should be noted that hysteresis was observed in the $\mathrm{J}-\mathrm{V}$ measurements and hence for a conservative estimate of the $\mu_{\mathrm{SCL}}$, forward sweep is considered. Moreover, factors like injection limited behavior have to be carefully considered to obtain the actual magnitude of $\mu_{S C L}$ in thin films. For TFSCL behavior, $\mathrm{J}(\mathrm{E}) \propto \mathrm{d}^{-3}$, hence devices were also fabricated with different thickness to confirm the TFSCL behavior compared to injection limited behavior. As evident from Figure S5, J(E) decreases with increased thickness for the perovskite films.

Nevertheless, under similar conditions upon addition of the monovalent cation additive, the $\mu_{\mathrm{SCL}}$ increased significantly (up to an order of magnitude) for holes compared to that for electrons. Hole mobility as high as $0.07 \mathrm{~cm}^{2} . \mathrm{V}^{-1} . \mathrm{s}^{-1}$ was obtained for $\mathrm{NaI}$ based perovskite thin films (Figure 

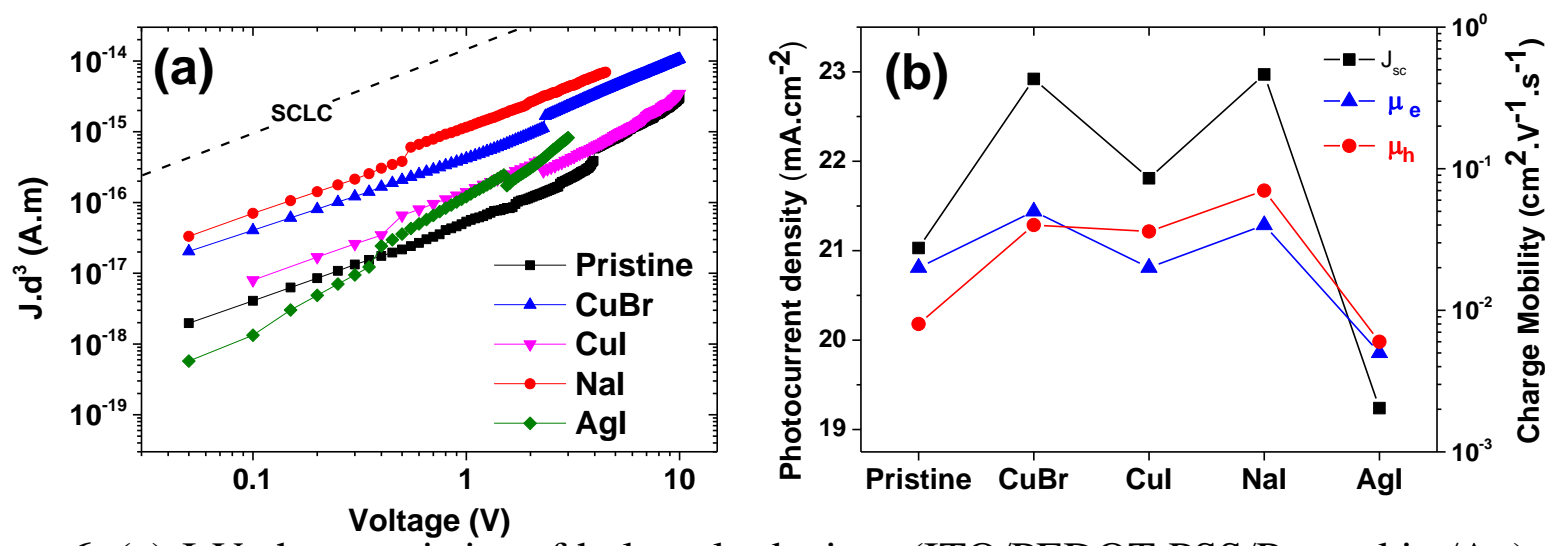

Figure 6. (a) J-V characteristics of hole only devices (ITO/PEDOT:PSS/Perovskite/Au), utilized for estimating the SCLC hole mobility. Note that the current density $(\mathrm{J})$ is scaled with thickness of perovskite layers. (b) The trends in the $\mathrm{J}_{\mathrm{sc}}, \mu_{\mathrm{h}}$ and $\mu_{\mathrm{e}}$ for pristine and additive based perovskite.

6b). However, electron mobility increased to around $0.04 \mathrm{~cm}^{2} / \mathrm{Vs}$ resulting in a more balanced charge transport. It should be noted that these values of bulk mobility are one of the highest in the community for perovskite thin films. Correspondingly, the conductivity magnitude estimated

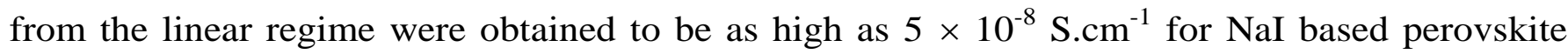
compared to $10^{-9} \mathrm{~S}_{\mathrm{cm}} \mathrm{cm}^{-1}$ for pristine films. It is evident from the charge transport measurements that the addition of monovalent cations strongly affect the balanced charge transport properties and the overall conductivity which is enhance the $\mathbf{J}_{\mathrm{sc}}$ of the solar cells (Figure $6 \mathrm{~b}$ ). Thus it can be concluded that one of the strategies to increase the $\mathbf{J}_{\mathrm{sc}}$ in perovskite solar cells could be to increase the balance between the bulk electron and hole transport.

To further understand the reason for the increased $\mu_{S C L}^{h}$ in additive based perovskite films, temperature dependent bulk transport measurements were performed. Arrhenius fits were utilized to estimate the activation energy $\left(\mathrm{E}_{\mathrm{A}}\right)$ for the charge transport (Table 1). Adding of monovalent cations in the perovskite films results in a decrease of $\mathrm{E}_{\mathrm{A}}$ for hole transport from $198 \mathrm{meV}$ to 137 $\mathrm{meV}$ and electron transport from $13 \mathrm{meV}$ to $77 \mathrm{meV}$. In the framework of a mobility edge model, it is expected that the increase in carrier concentration due to doping can result in filling up of the 
traps at the transport level and decrease the barrier for transport which can diminish the activation energy. This is consistent with the observed change in the Fermi level of perovskite upon the addition of monovalent cation halide additives. Hence, it is plausible that the presence of stable +1 oxidation states of the cations results in passivation of traps in the system. Thus, it can be concluded from the charge transport measurements that the addition of monovalent cation halide additive results in enhancing the overall mobility of the charge carriers which is expected to enhance the $\mathbf{J}_{\mathrm{sc}}$ of the perovskite solar cell devices.

\subsection{Photovoltaic performance}

Current density-voltage $(\mathrm{J}-\mathrm{V})$ characteristics of the pristine and additive based perovskite solar cells were measured under simulated air mass 1.5 global (AM1.5G) solar irradiation. The devices were fabricated based on the optimized procedure which is explained in the experimental section. A typical device has the structure of FTO/compact $\mathrm{TiO}_{2} /$ mesoporous $\mathrm{TiO}_{2} / \mathrm{CH}_{3} \mathrm{NH}_{3} \mathrm{PbI}_{3} / \mathrm{Spiro}$ MeOTAD/Au, shown in Figure S7.

The influence of additive concentration on the photovoltaic performance of PSC was demonstrated by examining three different concentrations of $\mathrm{CuBr}\left(0.01,0.02\right.$ and 0.04 mol. $\left.\mathrm{L}^{-1}\right)$ additive based perovskite devices (Figure S6). As summarized in Table S2, the lowest concentration slightly increased photocurrent density $\left(\mathrm{J}_{\mathrm{sc}}\right)$ by $0.5 \mathrm{~mA} \cdot \mathrm{cm}^{-2}$. By increasing the concentration of $\mathrm{CuBr}$ to $0.02 \mathrm{~mol} . \mathrm{L}^{-1}$ photovoltaic performance of the device revealed an average PCE of $15.4 \%$ while further increase in the amount of additive decreases $\mathrm{J}_{\mathrm{sc}}$ and open circuit voltage $\left(\mathrm{V}_{\mathrm{oc}}\right)$ which eventually brought down the overall power conversion efficiency (PCE) of the device. Therefore a concentration of 0.02 mol.L $\mathrm{L}^{-1}$ can be stated as the optimum level of the additive to realize the high performance of PSC.

Figure $7 \mathrm{a}$ and Table 1 show the influence of different additives on the photovoltaic parameters of 
Table 1. Summary of the photovoltaic parameters derived from $\mathrm{J}-\mathrm{V}$ measurements and charge mobilities along with activation energy for the pristine and additive based perovskite solar cells (showing the best performance) fabricated using two-step deposition method.

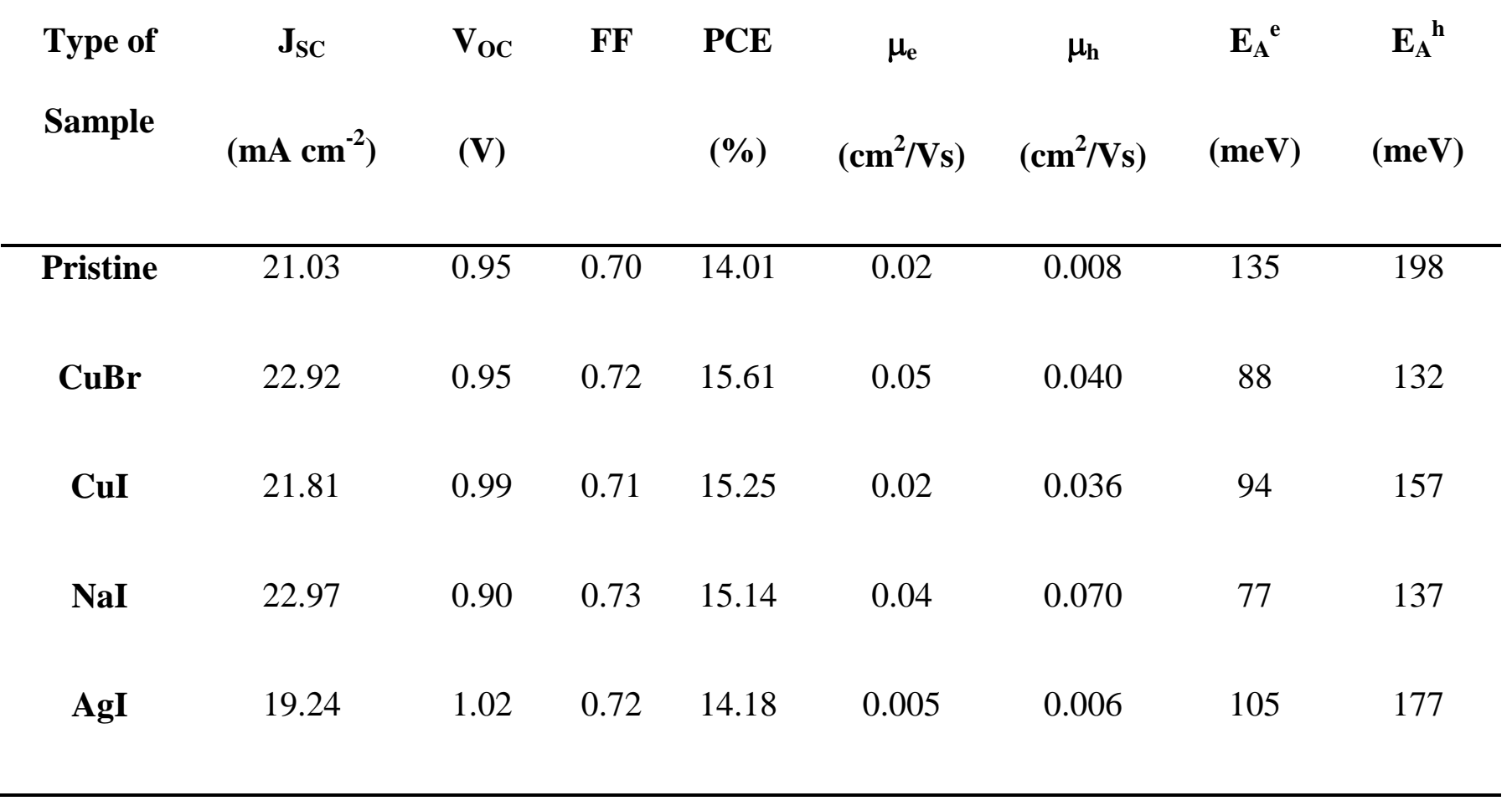

the PSC. It is notable that the statistics of the photovoltaic parameters follow the same trend as the best performing devices (Table S3). For the additive-free reference cell, $\mathrm{J}_{\mathrm{sc}}$ of $21.03 \mathrm{~mA} . \mathrm{cm}^{-2}, \mathrm{~V}_{\mathrm{oc}}$ of $0.95 \mathrm{~V}$, fill factor (FF) of 0.70 and PCE of $14.01 \%$ are achieved. The $\mathrm{J}_{\mathrm{sc}}$ of AgI based device dropped nearly by $2 \mathrm{~mA} \cdot \mathrm{cm}^{-2}$ compare to the pristine cell which could be attributed to the lower loading of $\mathrm{CH}_{3} \mathrm{NH}_{3} \mathrm{PbI}_{3}$ in $\mathrm{AgI}$ based sample (as it shows the lowest absorption in Figure 4b). On the other hand, because of the ideal surface coverage of AgI based perovskite, high $\mathrm{V}_{\text {OC }}$ of $1.02 \mathrm{~V}$ is achieved (Figure 1e). In addition, since the fill factor of AgI based device improved due to the relatively balanced charge transport (Figure 6a and Table 1), the overall efficiency of the device slightly improved to $14.18 \%$. 

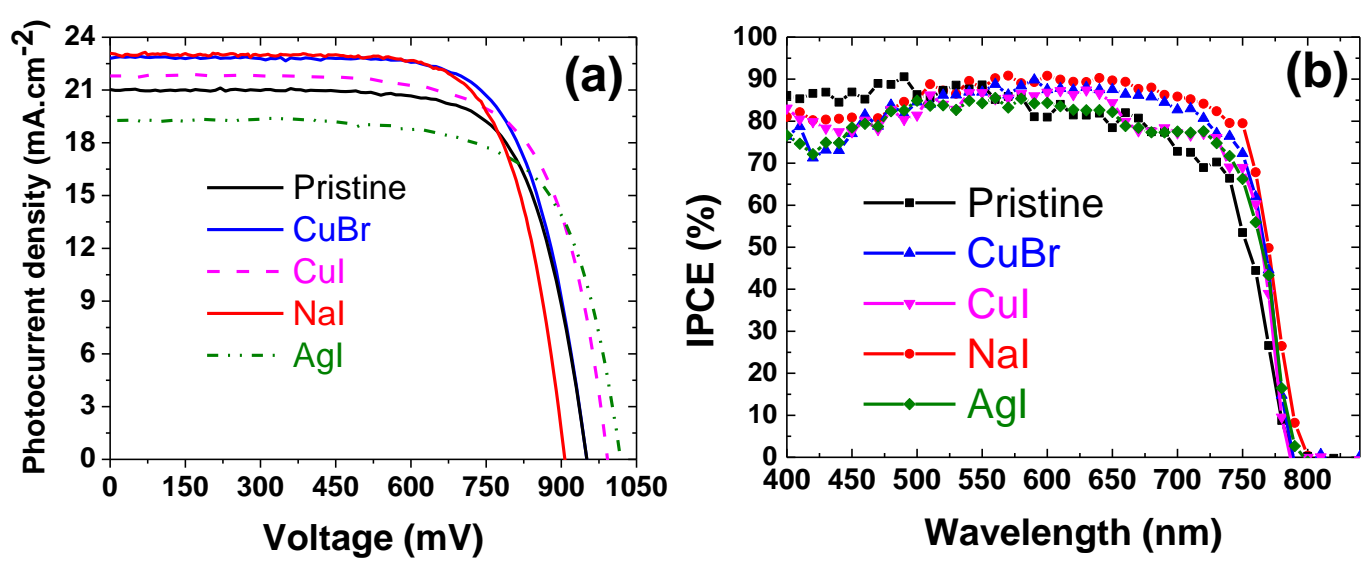

Figure 7. (a) Current-voltage characteristics of devices under illumination of $100 \mathrm{~mW}$ $\mathrm{cm}^{-2}$ obtained using different type of monovalent cation halide added to the lead source solution. (b) Incident photon-to-current efficiency (IPCE) spectra as a function of the wavelength of monochromatic light for the pristine, CuBr-, CuI-, NaI- and AgI-based perovskite solar cells.

Surprisingly, all other additives including $\mathrm{NaI}, \mathrm{CuBr}$ and $\mathrm{CuI}$ enhanced the PCE of PSC notably to $15.14 \%, 15.61 \%$ and $15.25 \%$, respectively. The open-circuit voltage of $\mathrm{CuBr}$ based device $(0.95 \mathrm{~V})$ was similar to that of pristine one while a considerable drop of around $50 \mathrm{mV}$ is noticed for $\mathrm{NaI}$ based cells $(0.90 \mathrm{~V})$. The lower voltage in $\mathrm{NaI}$ based derived samples can be explained due to the presence of increased shunting pathways because of detrimental contact between spiro-OMeTAD and mesoporous $\mathrm{TiO}_{2}$ layer which is quite expected from a rougher perovskite films, (SEM images in Figure 1d). In contrast, a uniform and pinhole free surface of $\mathrm{CuI}$ based $\mathrm{CH}_{3} \mathrm{NH}_{3} \mathrm{PbI}_{3}$ sample lead to the improvement in $\mathrm{V}_{\mathrm{oc}}(0.99 \mathrm{~V}$ vs $0.95 \mathrm{~V}$ for additive-free reference) (Figure 1c).

Moreover, a substantial enhancement in the $\mathrm{J}_{\mathrm{sc}}$ of $21.81 \mathrm{~mA} \cdot \mathrm{cm}^{-2}$ for CuI, 22.92 mA.cm ${ }^{-2}$ for $\mathrm{CuBr}$ and $22.97 \mathrm{~mA} . \mathrm{cm}^{-2}$ for NaI based devices compared to 21.03 


\section{WILEY-VCH}

mA.cm ${ }^{-2}$ for pristine solar cells was observed. The highest $\mathbf{J}_{\mathrm{sc}}$ exhibited by NaI based device can be attributed to the better conversion of $\mathrm{PbI}_{2}$ into $\mathrm{CH}_{3} \mathrm{NH}_{3} \mathrm{PbI}_{3}$ as revealed by XRD pattern (Figure 3) and therefore higher loading of perovskite inside the meso$\mathrm{TiO}_{2}$ scaffold which is consistent with the PDS data (Figure 4b). However, diminished photocurrent density observed in other samples, i.e., AgI could be attributed to the relatively low conversion of lead halide into $\mathrm{CH}_{3} \mathrm{NH}_{3} \mathrm{PbI}_{3}$ under given conditions. The enhancement in current densities of PSC based on $\mathrm{NaI}, \mathrm{CuBr}$ and CuI-based $\mathrm{CH}_{3} \mathrm{NH}_{3} \mathrm{PbI}_{3}$ are supported by the improvement in the incident photon to current conversion efficiency (IPCE) spectra shown in Figure 7b. In addition, IPCE of all the devices as a function of wavelength shows that the generation of photocurrent starts at around $780 \mathrm{~nm}$, which is in agreement with the band edge of pristine $\mathrm{CH}_{3} \mathrm{NH}_{3} \mathrm{PbI}_{3}$. This confirms further that the presence of additives does not change the band gap of the perovskite material which is consistent with PDS results. We also noticed that the fill factors (FFs) of devices based on the $\mathrm{NaI}$ and $\mathrm{CuBr}$ based perovskite improved noticeably, in comparison with the pristine reference cell. Arguably, improvement of FFs could be due to the enhancement in conductivity and presence of lower level of electronic disorder in the additive based $\mathrm{CH}_{3} \mathrm{NH}_{3} \mathrm{PbI}_{3}$ films (Figure $4 \mathrm{~b}, 6$ and Table 1).

\section{Conclusions}

In summary, we have systematically studied the role of the monovalent cation halide based additives on the morphological, optical and electrical properties of $\mathrm{CH}_{3} \mathrm{NH}_{3} \mathrm{PbI}_{3}$ perovskite films. We found that a better conversion of lead iodide into $\mathrm{CH}_{3} \mathrm{NH}_{3} \mathrm{PbI}_{3}$ structure is achieved for $\mathrm{NaI}$ and $\mathrm{CuBr}$ based films which was confirmed by XRD and, for $\mathrm{CuI}$ and $\mathrm{AgI}$ based perovskite a uniform film with a continuous coverage is formed. Detailed experiments based on PDS, KPFM and bulk transport measurements on the 


\section{WILEY-VCH}

pristine and additive based perovskites indicate that the additives can possibility cause a passivation of states at the crystallite surfaces. This minimizes the extrinsic doping at the crystallite boundaries and improves the overall charge transport properties as well as the solar cell performance. These observations indicate that the additives seem to passivate the hole traps in the surface (or grain boundaries) of perovskite films that results in an enhancement of $\mathrm{J}_{\mathrm{sc}}$ and hence, the overall efficiency of the solar cell. The confluence of aforementioned favourable properties led to the enhancement of PCE to $15.14 \%, 15.25 \%$ and $15.61 \%$ for $\mathrm{NaI}, \mathrm{CuI}$ and $\mathrm{CuBr}$, respectively, in comparison with $14.01 \%$ for the additive-free reference cell. The photovoltaic results, particularly for AgI based cell, confirm that the ideal surface coverage of perovskite is not the only sufficient factor to achieve a high efficiency but also a full conversion of lead iodide into the perovskite is required. In summary, this work demonstrates the possibility of enhancing the structural and optoelectronic properties that play a very crucial role in improving the performance of perovskite based solar cells by simple addition of a rational amount of low cost monovalent cation based inorganic salts.

\section{Experimental Section}

Materials. Unless stated otherwise, all materials were purchased from Sigma- Aldrich or Acros Organics and used as received. Spiro-MeOTAD was purchased from Merck KGaA. $\mathrm{CH}_{3} \mathrm{NH}_{3} \mathrm{I}$ was synthesized according to a reported procedure ${ }^{3}$.

Photoanode preparation. Devices were fabricated on laser patterned FTO-coated glass (NSG 10, Nippon sheet glass, Japan). Initially, FTO substrates were cleaned sequentially in 2\% Hellmanex detergent, 2-propanol and ethanol, and then treated with a ultraviolet $/ \mathrm{O}_{3}$ cleaner for $15 \mathrm{~min}$. A hole-blocking layer of compact $\mathrm{TiO}_{2}$ was deposited by spray pyrolysis using a precursor solution of titanium di-isopropoxide bis(acetylacetonate; $0.6 \mathrm{ml}$ titanium acetylacetonate in $8 \mathrm{ml}$ ethanol) on a hot plate at 


\section{WILEY-VCH}

$450{ }^{\circ} \mathrm{C}$. The titanium acetylacetonate was prepared by pouring acetylacetone (Wako Pure Chemical Industries, Ltd.) into titanium isopropoxide (Kanto Chemical Co., Inc.) with a mole ratio of $2: 1$. For the preparation of mesoporous $\mathrm{TiO}_{2}$ scaffold, a commercial $\mathrm{TiO}_{2}$ paste (Dyesol 30NRD) was diluted with ethanol (2:7, weight ratio) and was then deposited by spin coating at 5,000 r.p.m. for 30 s. After drying at $125{ }^{\circ} \mathrm{C}$, the $\mathrm{TiO}_{2}$ films were gradually heated to $500{ }^{\circ} \mathrm{C}$ and annealed at this temperature for 20 $\min$.

Synthesis and deposition of pristine and additive based $\mathrm{CH}_{3} \mathrm{NH}_{3} \mathrm{PbI}_{3} \cdot \mathrm{PbI}_{2}$ was dissolved in N,N-dimethylformamide (DMF) at a concentration of $1.2 \mathrm{M}$ under constant stirring at $80{ }^{\circ} \mathrm{C}$. The halide salts including $\mathrm{NaI}, \mathrm{CuBr}, \mathrm{CuI}$ and $\mathrm{AgI}$ were then added to the lead halide solution at a concentration of $0.02 \mathrm{M}$. All the solution were prepared inside an argon glove box under moisture- and oxygen-controlled conditions $\left(\mathrm{H}_{2} \mathrm{O}\right.$ level: $<1 \mathrm{ppm}$ and $\mathrm{O}_{2}$ level: $\left.<10 \mathrm{ppm}\right)$. The $\mathrm{CH}_{3} \mathrm{NH}_{3} \mathrm{PbI}_{3}$ films were prepared using two-step deposition method ${ }^{[6]}$. In the first step, the mesoporous $\mathrm{TiO}_{2}$ was infiltrated with pure or additive based $\mathrm{PbI}_{2}$ solution by spin coating at $6500 \mathrm{rpm}$ for $30 \mathrm{~s}$ and dried at $80{ }^{\circ} \mathrm{C}$ for $30 \mathrm{~min}$., To form perovskite resulting $\mathrm{PbI}_{2}$ films were dipped in a solution of $\mathrm{CH}_{3} \mathrm{NH}_{3} \mathrm{I}$ in 2-propanol $\left(8 \mathrm{mg} \mathrm{mL}^{-1}\right)$ for $30 \mathrm{~s}$, and were dried at $80{ }^{\circ} \mathrm{C}$ for $30 \mathrm{~min}$ after cooling to room temperature

Solar cells fabrication. After infiltration of $\mathrm{TiO}_{2}$ scaffold with pure and additive based $\mathrm{CH}_{3} \mathrm{NH}_{3} \mathrm{PbI}_{3}$, the hole transport material (HTM) was deposited by spin coating at 4,000 rpm for $30 \mathrm{~s}$. The spin coating formulation of HTM was prepared by dissolving $72.3 \mathrm{mg}$ spiro-MeOTAD, $28.8 \mathrm{ml}$ 4-tert-butylpyridine, $17.5 \mathrm{ml}$ of a stock solution of $520 \mathrm{mgml}^{-1}$ lithium bis (trifluoromethylsulphonyl) imide in acetonitrile and $29 \mathrm{ml}$ of a stock solution of $300 \mathrm{mgml}^{-1}$ tris(2-(1H-pyrazol-1-yl)-4-tert-butylpyridine) cobalt(III) bis (trifluoromethyl sulphonyl) imide in acetonitrile in $1 \mathrm{ml}$ chlorobenzene. Finally, 


\section{WILEY-VCH}

70nm of gold was thermally evaporated on top of the device to form the back contact. The device fabrication was carried out under controlled atmospheric conditions with a humidity of $<1 \%$.

Material characterization. Field-emission scanning electron microscope (FESEM, Merlin) was employed to examine morphology of the pristine and additive based perovskite films. An electron beam accelerated to $3 \mathrm{kV}$ was used with an in-lens detector. The atomic force microscope (AFM) images were obtained using a Thermo Microscope M5 in non-contact mode and scanning over a range of $15 \mu \mathrm{m}$ by $15 \mu \mathrm{m}$ at a resolution of $256 \times 256$ data points. The surface roughness was measured as the root mean-squared roughness over the scanning area. $2 \theta$ scans were obtained from samples of perovskite deposited on the mesoporous $\mathrm{TiO}_{2}$-coated FTO glass using Bruker Advance D8 X-ray diffractometer with a graphite monochromator, using $\mathrm{Cu}-\mathrm{K}_{\alpha}$ radiation, at a scanning rate of $0.5 \mathrm{deg} \cdot \mathrm{min}^{-1}$. X-ray photoelectron spectroscopy (XPS) was performed on an X-ray photoelectron spectrometer (ESCALAB 250Xi, Thermo Fisher SCIENTIFIC INC., USA) with $\mathrm{Al} \mathrm{K} \alpha$ radiation(hv=1486.6 eV) as the source.

Optical characterization. The steady state optical properties of perovskite films were studied using UV-visible absorption and fluorescence spectroscopy. The absorption spectra of perovskite films were recorded with convenient UV-Vis-NIR spectrophotometer (CARY-5) in transmission mode. Fluorescence spectra and fluorescence decay kinetics were recorded on a spectrofluorometer Fluorolog 322 . Fluorescence spectra were recorded by exciting the samples with $450 \mathrm{~W}$ Xenon lamp at a fixed wavelength of $460 \mathrm{~nm}$ and scanning the emission monochromator from 500 to $850 \mathrm{~nm}$. Same spectrometer working in a single-photon counting mode was used for the measurements of fluorescence decay kinetics with sub-nanosecond time resolution. Picosecond pulsed diode laser head NanoLED-405LH (Horiba) emitting <200 ps 


\section{WILEY-VCH}

duration pulses at $406 \mathrm{~nm}$ with repetition rate of $1 \mathrm{MHz}$ and pulse energy about $11 \mathrm{pJ}$ was use as an excitation source.

Photothermal deflection spectroscopy (PDS). PDS as a scatter-free surface sensitive absorption measurement were performed on the pristine and additive based perovskite films. Samples prepared in an identical fashion to the solar cell preparation were spun onto spectrosil quartz slides (which were cleaned with acetone, isopropanol, and water followed by a 10 min oxygen plasma etch). For this particular measurement, we made use of quartz rather than the FTO-coated glass to minimize light absorption by the substrate. During the measurement we kept the samples in a hermetically sealed quartz cuvette filled with an inert liquid, Fluorinert FC-72 from 3M Corporation, which acts as the deflection medium with high temperature dependent refractive index. We excited the perovskite films with a modulated monochromated light beam perpendicular to the plane of the sample. A modulated monochromated light beam was produced by a combination of a Light Support MKII 100W Xenon arc source and a CVI DK240 monochromator. The transverse probe beam was produced with Qioptiq 670-nm fibre-coupled diode laser and passed as close as possible to the perovskite film surface. Beam deflection was measured using a differentially amplified quadrant photodiode and a Stanford Research SR830 lock-in amplifier which is proportional to the absorption in the sample.

Kelvin probe measurement. Our KPFM apparatus is a Veeco Dimension 3100 system operated in ambient atmosphere. This system was selected due to its ability of scanning over a length of $80 \mu \mathrm{m}$. The PtIr tip (Bruker, SCM-PIT, 60-100k Hz), which has a work function of about $4.85 \mathrm{eV}$ was used for this measurement. The oscillation of the tip is controlled in an amplitude-modulation (AM) mode. 


\section{WILEY-VCH}

Diode for SCLC measurement. Devices were fabricated on pre-cleaned ITO substrates (15 ohm.Sq ${ }^{-1}$ ), obtained from XINYAN Technology Ltd. For hole only devices (ITO/PEDOT:PSS/Perovskite/Au), PEDOT:PSS was spin coated at $2000 \mathrm{rpm}$ and annealed at $180^{\circ} \mathrm{C}$ for 1 hour in air. Perovskite films both pristine and doped were obtained by a two-step deposition process as described earlier to obtain films of thickness $0.5-1 \mu \mathrm{m}$. Similarly electron only devices (ITO/Perovskite/PCBM/Al) were fabricated. Thin PCBM layer of around 20- $30 \mathrm{~nm}$ was utilized to prevent the degradation of the $\mathrm{Al}$ electrode due to the perovskite. It was ensured that the presence of a thin layer of PCBM does not significantly degrade the electron transport of the perovskite. Metal electrodes were coated by thermal evaporation $\left(10^{-6}\right.$ mbar, $0.1 \mathrm{~A}^{0} / \mathrm{s}$, $60 \mathrm{~nm}$ thick). The devices were characterized using Keithley 4200 SCS and temperature was varied using a RF probe station from Cryogenic Technologies.

Solar cell characterization. Current-voltage characteristics were recorded by applying an external potential bias to the cell while recording the generated photocurrent with a digital source meter (Keithley Model 2400). The light source was a 450-W xenon lamp (Oriel) equippedwith a Schott-K113 Tempax sunlight filter (Praezisions Glas \& OptikGmbH) to match the emission spectrum of the lamp to the AM1.5G standard. Before each measurement, the exact light intensity was determined using a calibrated $\mathrm{Si}$ reference diode equipped with an infrared cut-off filter (KG-3, Schott). IPCE spectra were recorded as a function of wavelength under a constant white light bias of approximately $5 \mathrm{mWcm}^{-2}$ supplied by an array of white light emitting diodes. The excitation beam coming from a 300-W xenon lamp (ILC Technology) was focused through a Gemini-180 double monochromator (Jobin Yvon Ltd) and chopped at approximately $2 \mathrm{~Hz}$. The signal was recorded using a Model SR830 DSP Lock-In Amplifier (Stanford Research Systems). All measurements were 


\section{WILEY-VCH}

conducted using a non-reflective metal aperture of $0.159 \mathrm{~cm}^{2}$ to define the active area of the device and avoid light scattering through the sides.

The data underlying this paper are available at https://www.repository.cam.ac.uk/handle/1810/254105.

\section{Supporting Information}

Macroscopic pictures, lifetime measurement, $\mathrm{PDS}$ spectra of $\mathrm{PbI}_{2}$ and perovskite, data fittings of Urbach energy, thickness dependency of charge mobility measurement, current-voltage curves and table containing the photovoltaic parameters derived from JV curves obtained from a batch of devices, SEM cross sectional micrographs of a complete device, thickness measurement by profilometer, FWHM values from the XRD patterns, forward and reverse JV scans, normalized PCE of devices as function of time and XPS measurement are provided in in Supporting Information which is available from the Wiley Online Library or from the author.

\section{Acknowledgements}

M.A.J. thanks Nyak Technology Limited for a PhD scholarship. R.H.F, M.A.J., and A.S. would like to acknowledge the support from EPSRC. M.I.D., S.M.Z., and M.G. thank the King Abdulaziz City for Science and Technology (KACST) and Swiss National Science Foundation (SNSF) for financial support. N.A. gratefully acknowledges financial support from the Swiss confederation under Swiss Government Scholarship program. The authors would like to thank Dr. Pierre Mettraux in Molecular and Hybrid Materials Characterization Center, EPFL for carrying out XPS measurements. A.S. gratefully acknowledges financial support from the Indo-UK APEX project. S.P.S. acknowledges Royal Scociety London for the Newton Fellowship. 


\section{WILEY-VCH}

[1] A. Kojima, K. Teshima, Y. Shirai, T. Miyasaka, J. Am. Chem. Soc. 2009, 131, 6050.

[2] H.-S. Kim, C.-R. Lee, J.-H. Im, K.-B. Lee, T. Moehl, A. Marchioro, S.-J. Moon, R. Humphry-Baker, J.-H. Yum, J. E. Moser, M. Grätzel, N.-G. Park, Sci. Rep. 2012, 2, 591.

[3] D. Liu, T. L. Kelly, Nat. Photonics 2013, 8, 133.

[4] Q. Dong, Y. Fang, Y. Shao, P. Mulligan, J. Qiu, L. Cao, J. Huang, Science 2015, 347, 967-970.

[5] J. H. Noh, S. H. Im, J. H. Heo, T. N. Mandal, S. Il Seok, Nano Lett. 2013, 13, 1764.

[6] J. Burschka, N. Pellet, S.-J. J. Moon, R. Humphry-Baker, P. Gao, M. K. Nazeeruddin, M. Grätzel, M. Gratzel, Nature 2013, 499, 316.

[7] M. Grätzel, S. Seok, Nat. Photonics 2013, 7.

[8] M. M. Lee, J. Teuscher, T. Miyasaka, T. N. Murakami, H. J. Snaith, Science 2012, 338, 643-647.

[9] M. Liu, M. B. Johnston, H. J. Snaith, Nature 2013, 501, 395.

[10] W. S. Yang, J. H. Noh, N. J. Jeon, Y. C. Kim, S. Ryu, J. Seo, S. Il Seok, Science, 2015, $12,1234-1237$.

[11] B. Nicholson, S. Verma, P. Med, Science 2015, 345, 542-546.

[12] N. J. Jeon, J. H. Noh, W. S. Yang, Y. C. Kim, S. Ryu, J. Seo, S. Il Seok, Nature 2014, $517,476$.

[13] Y. Zhou, M. Yang, W. Wu, A. L. Vasiliev, K. Zhu, N. P. Padture, J. Mater. Chem. A 2015, 3, 8178 .

[14] M. A. Green, A. Ho-Baillie, H. J. Snaith, Nat. Photonics 2014, 8, 506.

[15] M. J. Carnie, C. Charbonneau, M. L. Davies, J. Troughton, T. M. Watson, K.

Wojciechowski, H. Snaith, D. a Worsley, Chem. Commun. (Camb). 2013, 49, 7893.

[16] J.-H. Im, I.-H. Jang, N. Pellet, M. Grätzel, N.-G. Park, Nat. Nanotechnol. 2014, 9, 927.

[17] Z. Cheng, J. Lin, CrystEngComm 2010, 12, 2646.

[18] W. Nie, H. Tsai, R. Asadpour, J. Blancon, A. J. Neukirch, G. Gupta, J. J. Crochet, M. Chhowalla, S. Tretiak, M. A. Alam, H. Wang, A. D. Mohite, Science 2015, 347, 522525.

[19] S. D. Stranks, G. E. Eperon, G. Grancini, C. Menelaou, M. J. P. Alcocer, T. Leijtens, L. M. Herz, A. Petrozza, H. J. Snaith, Science 2013, 342, 341-345. 


\section{WILEY-VCH}

[20] W. Zhang, M. Saliba, D. T. Moore, S. K. Pathak, M. T. Ho, T. Stergiopoulos, S. D. Stranks, G. E. Eperon, J. A. Alexander-webber, A. Abate, A. Sadhanala, S. Yao, Y. Chen, R. H. Friend, L. A. Estroff, U. Wiesner, H. J. Snaith, Nat. Commun., 2015, 6, 7142.

[21] J. Navas, A. Sanchez-Coronilla, J. J. Gallardo, N. Cruz Hernández, J. C. Pinero, R. Alcántara, C. Fernández-Lorenzo, D. M. de los Santos, T. Aguilar, J. Martín-Calleja, Nanoscale 2015, 7, 6216-6229.

[22] N. Pellet, P. Gao, G. Gregori, T. Y. Yang, M. K. Nazeeruddin, J. Maier, M. Grätzel, Angew. Chemie - Int. Ed. 2014, 53, 3151.

[23] Y. Ogomi, A. Morita, S. Tsukamoto, T. Saitho, N. Fujikawa, Q. Shen, T. Toyoda, K. Yoshino, S. S. Pandey, S. Hayase, J. Phys. Chem. Lett. 2014, 5 (6), 1004-1011.

[24] F. Hao, C. C. Stoumpos, R. P. H. Chang, M. G. Kanatzidis, J. Am. Chem. Soc. 2014, $136,8094$.

[25] Y. Zhou, M. Yang, A. L. Vasiliev, H. F. Garces, J. Mater. Chem. A Mater. energy Sustain. 2015, 00, 1.

[26] M. I. Dar, N. Arora, P. Gao, S. Ahmad, M. Gratzel, M. K. Nazeerudding, J. Phys. Chem. Lett. 2014, 5 (6), 1004-1011.

[27] K. Liang, D. Mitzi, M. Prikas, Chem. Mater. 1998, 4756, 403.

[28] G. Niu, X. Guo, L. Wang, J. Mater. Chem. A 2015, Advance.

[29] T. Baikie, Y. Fang, J. M. Kadro, M. Schreyer, F. Wei, S. G. Mhaisalkar, M. Gratzel, T. J. White, J. Mater. Chem. A 2013, 1, 5628.

[30] a. L. Patterson, Phys. Rev. 1939, 56, 978.

[31] S. De Wolf, J. Holovsky, S.-J. Moon, P. Löper, B. Niesen, M. Ledinsky, F.-J. Haug, J. Yum, C. Ballif, S. De Wolf, J. Phys. Chem. Lett. 2014, 5, 1035-1039.

[32] C. Wehrenfennig, M. Liu, H. J. Snaith, M. B. Johnston, L. M. Herz, J. Phys. Chem. Lett. 2014, 5, 1300.

[33] A. Sadhanala, F. Deschler, T. H. Thomas, E. Dutton, K. C. Goedel, F. C. Hanusch, M. L. Lai, U. Steiner, T. Bein, P. Docampo, D. Cahen, R. H. Friend, J. Phys. Chem. Lett. 2014, 5 (15), 2501-2505.

[34] J. Kim, S. H. Lee, J. H. Lee, K. H. Hong, J. Phys. Chem. Lett. 2014, 5, 1312.

[35] M. Nonnenmacher, M. P. O’Boyle, H. K. Wickramasinghe, Appl. Phys. Lett. 1991, 58, 2921. 


\section{WILEY-VCH}

[36] G. Elias, T. Glatzel, E. Meyer, A. Schwarzman, A. Boag, Y. Rosenwaks, Beilstein J. Nanotechnol. 2011, 2, 252.

[37] I. Visoly-Fisher, S. R. Cohen, D. Cahen, C. S. Ferekides, Appl. Phys. Lett. 2003, 83, 4924.

[38] C. S. Jiang, F. S. Hasoon, H. R. Moutinho, H. a. Al-Thani, M. J. Romero, M. M. AlJassim, Appl. Phys. Lett. 2003, 82, 127.

[39] E. Edri, S. Kirmayer, A. Henning, S. Mukhopadhyay, K. Gartsman, Y. Rosenwaks, G. Hodes, D. Cahen, Nano Lett. 2014, 14, 1000.

[40] P. Qin, A. L. Domanski, A. K. Chandiran, R. Berger, H.-J. Butt, M. I. Dar, T. Moehl, N. Tetreault, P. Gao, S. Ahmad, M. K. Nazeeruddin, M. Grätzel, Nanoscale 2014, 6, 1508.

[41] V. W. Bergmann, S. a. L. Weber, F. Javier Ramos, M. K. Nazeeruddin, M. Grätzel, D. Li, A. L. Domanski, I. Lieberwirth, S. Ahmad, R. Berger, Nat. Commun. 2014, 5, 5001.

[42] A. Dymshits, A. Henning, G. Segev, Y. Rosenwaks, L. Etgar, Sci. Rep. 2015, 5, 8704.

[43] M. Cargnello, A. C. Johnston-Peck, B. T. Diroll, E. Wong, B. Datta, D. Damodhar, V. V. T. Doan-Nguyen, A. a. Herzing, C. R. Kagan, C. B. Murray, Nature 2015, 524, 450.

[44] D. Shi, V. Adinolfi, R. Comin, M. Yuan, E. Alarousu, A. Buin, Y. Chen, S. Hoogland, A. Rothenberger, K. Katsiev, Y. Losovyj, X. Zhang, P. A. Dowben, O. F. Mohammed, E. H. Sargent, O. M. Bakr, Science 2015, 347, 519-522.

[45] S. P. Senanayak, a Z. Ashar, C. Kanimozhi, S. Patil, K. S. Narayan, Phys. Rev. B, 2015, 91, 115302. 


\section{WILEY-VCH}

\section{The table of contents entry}

Incorporation of monovalent cation halide additives improve the semiconductor behaviour and photovoltaic performance of $\mathrm{CH}_{3} \mathrm{NH}_{3} \mathrm{PbI}_{3}$ perovskite through formation of uniform and continuous perovskite film, better conversion and loading of $\mathrm{CH}_{3} \mathrm{NH}_{3} \mathrm{PbI}_{3}$ and possible passivation of defects states at the crystallite surfaces as well as the enhancement in the bulk charge transport along with a minimization of disorder.

Keywords: Monovalent cation halide, additives, $\mathrm{CH}_{3} \mathrm{NH}_{3} \mathrm{PbI}_{3}$ Perovskite, doping, surface passivation

Mojtaba Abdi-Jalebi, M. Ibrahim Dar, * Aditya Sadhanala, Satyaprasad P. Senanayak, Marius Franckevičius, Neha Arora, Yuanyuan Hu, Mohammad Khaja Nazeeruddin, Shaik M. Zakeeruddin, Michael Grätzel, * Richard H. Friend*

Impact of monovalent cation halide additives on the structural and optoelectronic properties of $\mathrm{CH}_{3} \mathrm{NH}_{3} \mathrm{PbI}_{3}$ perovskite

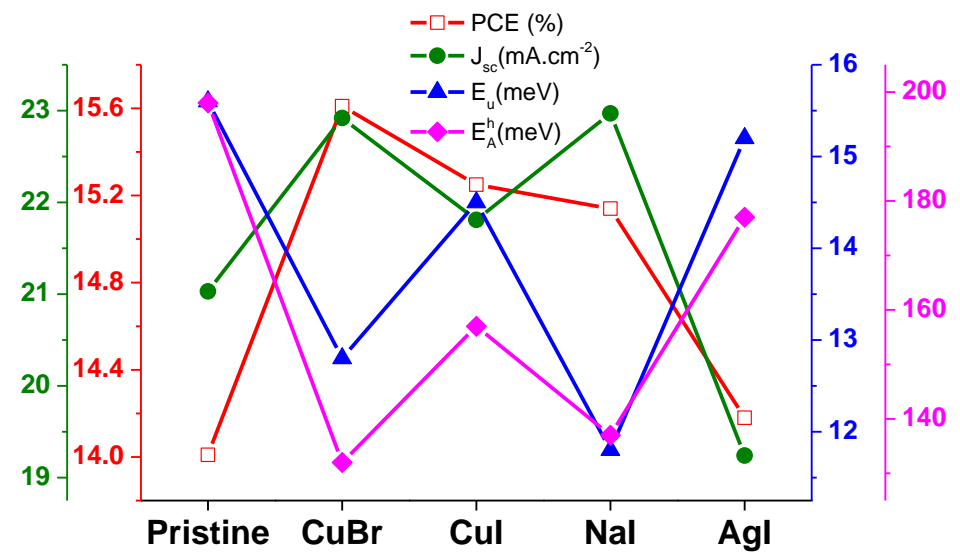




\section{WILEY-VCH}

\section{Supporting Information}

Impact of monovalent cation halide additives on the structural and optoelectronic properties of $\mathrm{CH}_{3} \mathrm{NH}_{3} \mathrm{PbI}_{3}$ perovskite

Mojtaba Abdi-Jalebi, Mohammad Ibrahim Dar,* Aditya Sadhanala, Satyaprasad P.

Senanayak, Marius Franckevičius, Neha Arora, Yuanyuan Hu, Shaik Mohammad Zakeeruddin, Mohammad Khaja Nazeeruddin, Michael Grätzel,* Richard H. Friend* 


\section{WILEY-VCH}
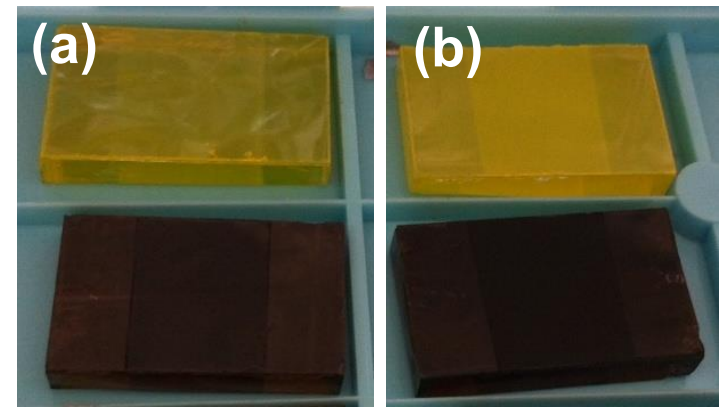

Figure S1. Macroscopic pictures of $\mathrm{PbI}_{2}$ (top) and $\mathrm{CH}_{3} \mathrm{NH}_{3} \mathrm{PbI}_{3}$ (bottom) films for (a) pristine and (b) NaI-based samples. 


\section{WILEY-VCH}

\section{Lifetime measurements}

Although the addition of additive does not modify the bandgap of $\mathrm{CH}_{3} \mathrm{NH}_{3} \mathrm{PbI}_{3}$ perovskite, the presence of low amount of additives can influence free or bound carrier dynamics. To estimate the charge carrier lifetimes, we performed photoluminescence lifetime measurements using time-correlated single photon counting. Photoluminescence decay kinetics of perovskite films deposited on mesoporous $\mathrm{TiO}_{2}$ in the absence of hole transport materials (HTM) are shown in Fig. 4b. PL traces for all investigated samples can be approximated by exponential functions containing two time constants. The estimated PL lifetimes and their relative contributions are summarized in Table S1. It is evident that PL decay kinetics experience several important differences depending on the type of additive. In comparison to pristine sample a fast PL decay component becomes slightly slower whereas long lived decay becomes accelerated in additive based samples. Moreover, the contribution

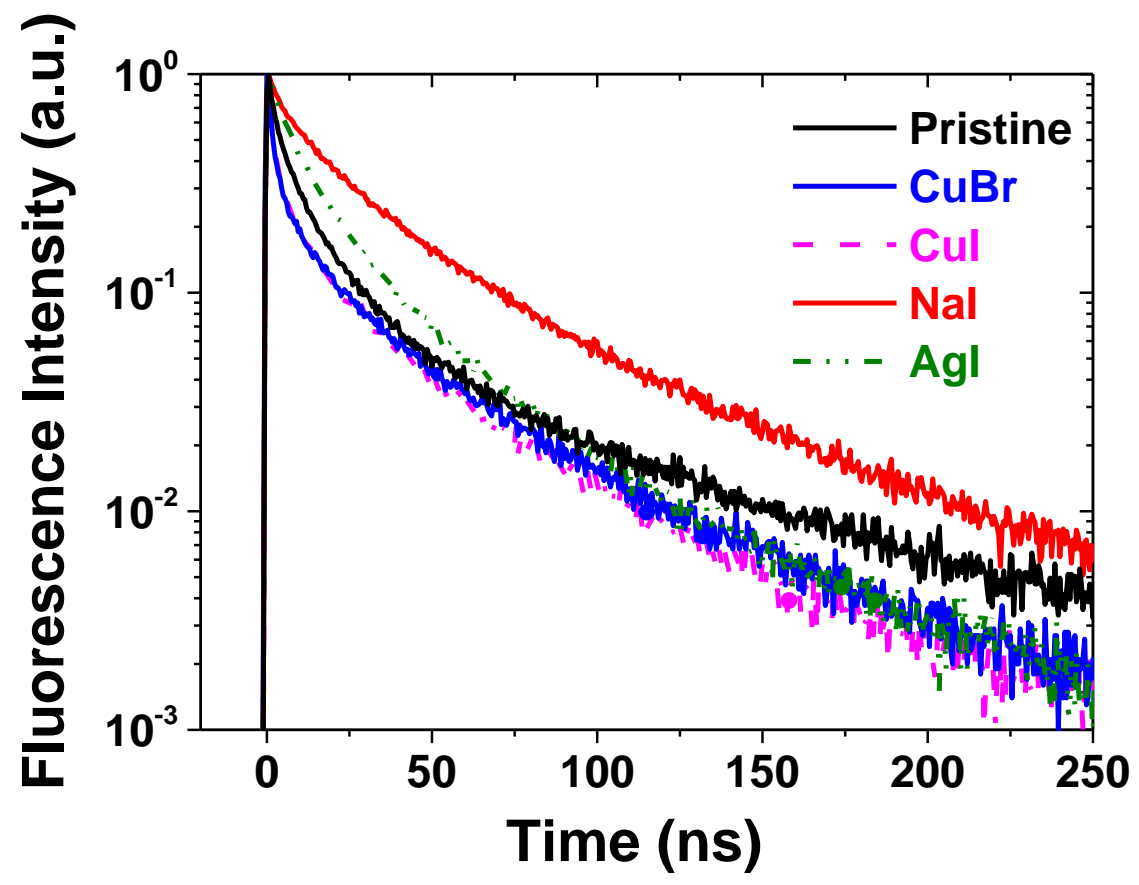

Figure S2. Fluorescence decay kinetics measured at $780 \mathrm{~nm}$ upon excitation at $406 \mathrm{~nm}$ with fluence of $11 \mathrm{pJ} . \mathrm{cm}^{-2}$ for pristine and additives based perovskite films. 


\section{WILEY-VCH}

of $\tau_{1}$ relaxation components became slightly higher (>50\%) upon addition of silver and sodium iodides, whereas its contribution decreases significantly for copper halide based samples. These observations can have implications in the recombination processes and disorder dynamics. However, a detailed analysis of these is beyond the scope of this work. 


\section{WILEY-VCH}

Table S1. The summarized emission lifetime " $\tau$ " and corresponding intensities "A" for various perovskite samples obtained using three exponential fit.

\begin{tabular}{lccccc}
\hline & Ref & CuI & CuBr & NaI & AgI \\
\hline $\mathbf{A}_{\mathbf{1}}, \%$ & 32.6 & 18.2 & 17.8 & 57.4 & 43.8 \\
$\tau_{1}, \mathbf{n s}$ & 17.6 & 20.8 & 21.25 & 22.3 & 20.7 \\
$\mathbf{A}_{2}, \boldsymbol{\%}$ & 5.6 & 5.2 & 5.6 & 18 & 6.7 \\
$\tau_{2}, \mathbf{n s}$ & 87.7 & 64.5 & 69.2 & 72.7 & 63.6 \\
\hline
\end{tabular}




\section{WILEY-VCH}
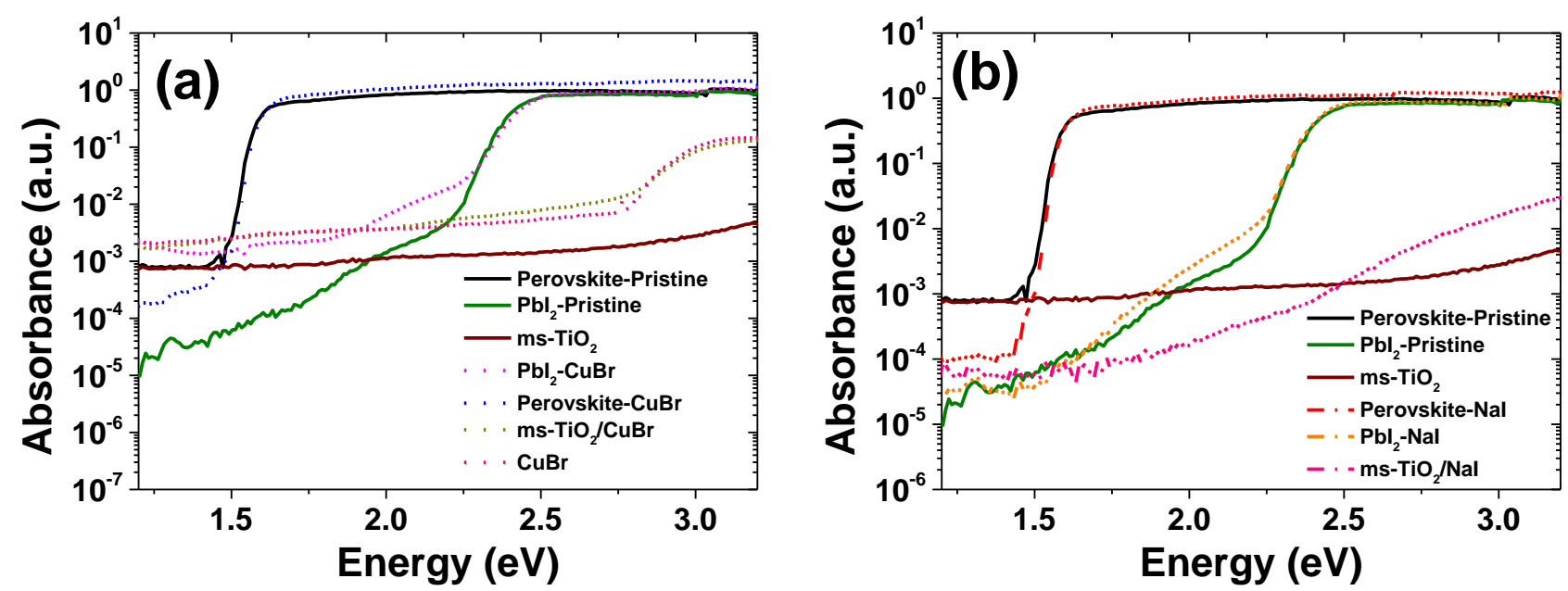

Figure S3. The absorption spectra of pristine and additive based lead iodide and perovskite films as well as additive deposited on $\mathrm{ms}^{-\mathrm{TiO}_{2}}$ and additive only films measured using the PDS technique. 


\section{WILEY-VCH}
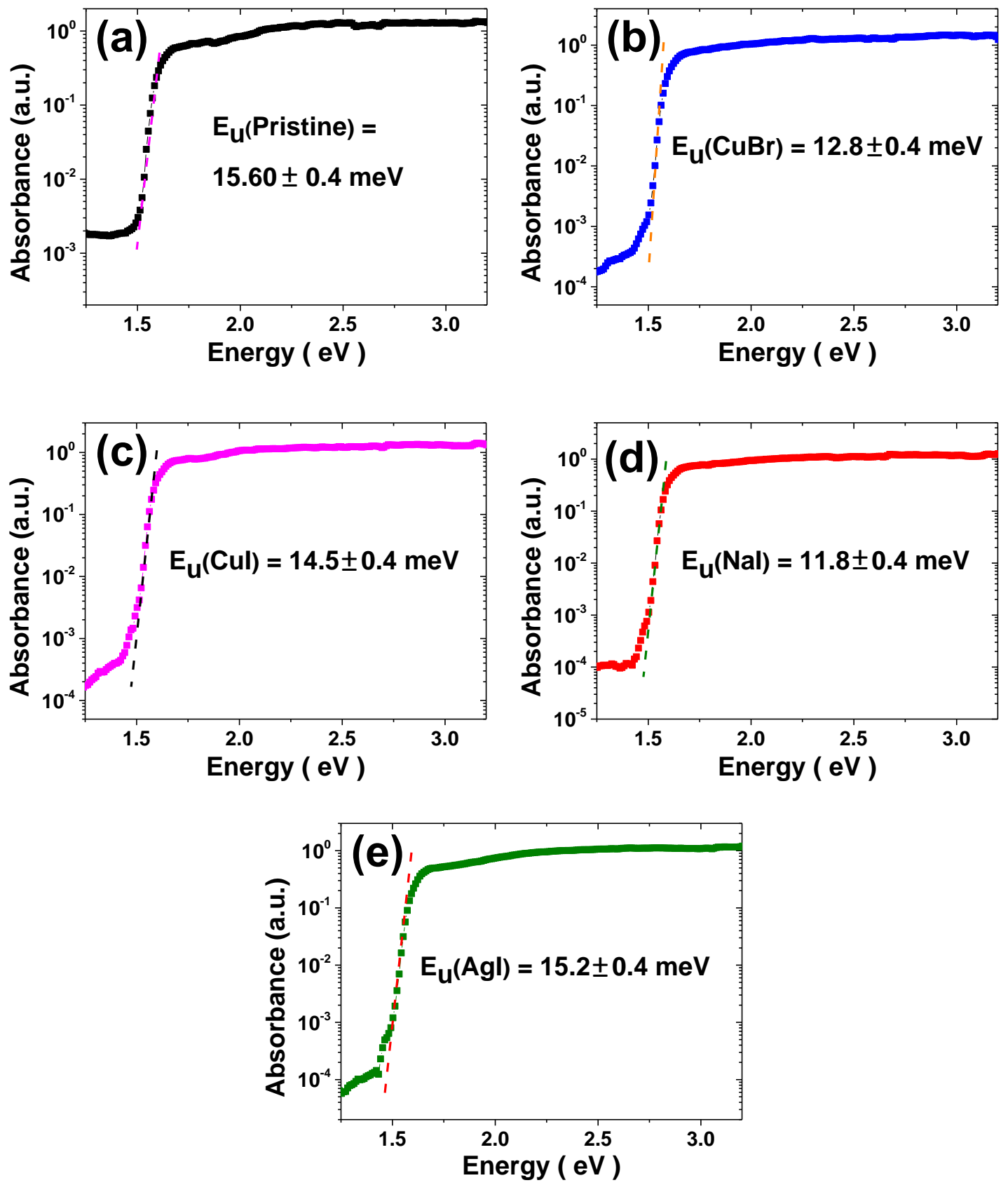

Figure S4. Data fittings of Urbach energy for PDS measurements of perovskite films prepared from (a) pure $\mathrm{PbI}_{2}$, (b) $\mathrm{CuBr}$, (c) $\mathrm{CuI}$, (d) NaI and (e) $\mathrm{AgI}$ based lead iodide. The dotted lines in each plot are the linear fits used to calculate the Urbach energy and the obtained Urbach energy 'Eu' is indicated in each plot. The error indicated in each plot is due to the s.d. in fitting the Urbach tail. 


\section{WILEY-VCH}

\section{Thickness dependency of charge mobility measurement}

As evident from the figure only a small variation of thickness was possible for the devices. It should be noted that varying the thickness of the films in perovskite affects the conversion of the perovskite layer, crystallinity of the material and thus the defect density. Hence, to ensure proper comparison between different thicknesses, devices were carefully chosen such that the current density is minimally affected by external parameters like coverage, crystallite size and grain boundary density for a particular type of materials.

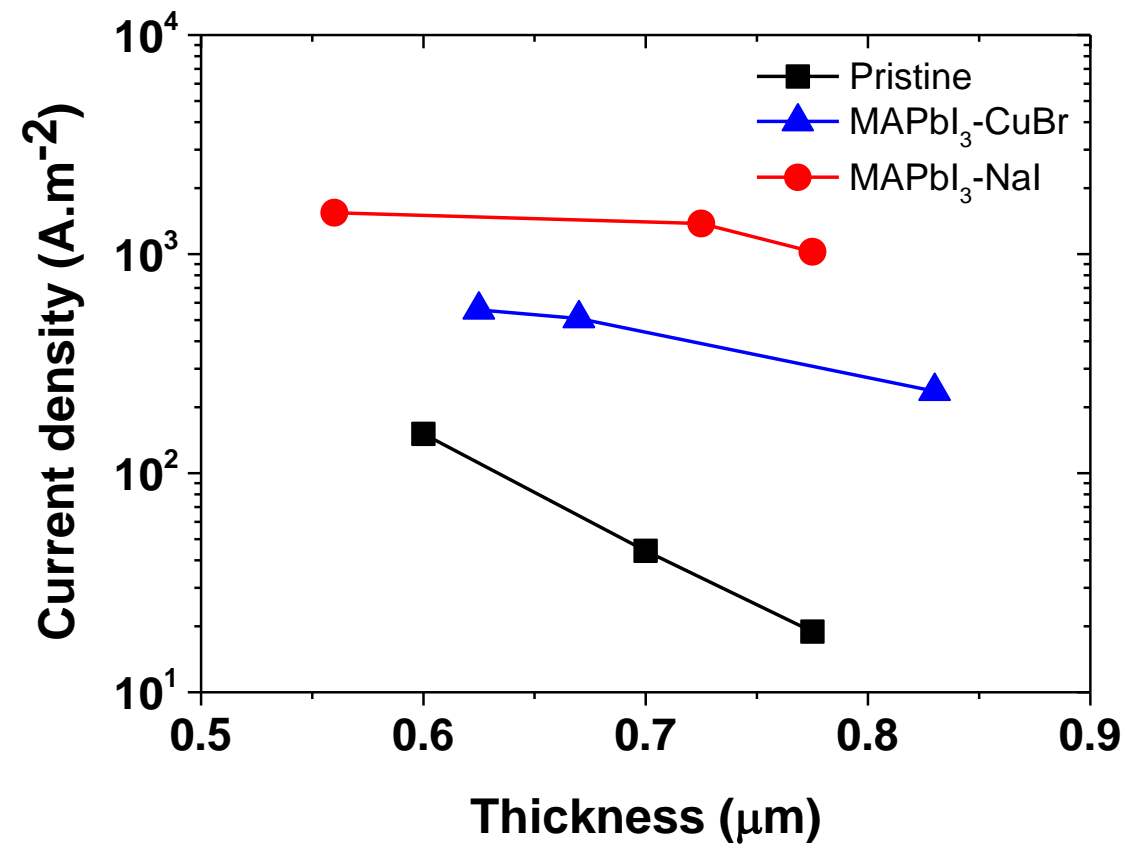

Figure S5. Thickness dependency of measured current density using SCLC method for pristine, $\mathrm{CuBr}$ and $\mathrm{NaI}$ based perovskite. 


\section{WILEY-VCH}

Table S2. Summary of the photovoltaic parameters derived from J-V measurements for the pristine and $\mathrm{CuBr}$ based perovskite solar cells (batch of 30 devices) with various concentration fabricated using two-step deposition method.

\begin{tabular}{cccccc}
$\begin{array}{c}\text { Type of } \\
\text { Sample }\end{array}$ & $\begin{array}{c}\text { Dopant Concentration } \\
\left(\mathrm{mol.}^{-1}\right)\end{array}$ & $\begin{array}{c}\mathrm{J}_{\mathrm{SC}} \\
\left(\mathrm{mA} \mathrm{cm}^{-2}\right)\end{array}$ & $\begin{array}{c}\mathrm{V}_{\mathrm{OC}} \\
(\mathrm{mV})\end{array}$ & FF & $\begin{array}{c}\text { PCE } \\
(\%)\end{array}$ \\
\hline Pristine & - & $20.7 \pm 0.4$ & $945 \pm 13$ & $0.69 \pm 0.02$ & $13.7 \pm 0.3$ \\
& & & & & \\
$\mathrm{CuBr}$ & 0.01 & $22.1 \pm 0.6$ & $921 \pm 10$ & $0.69 \pm 0.03$ & $14.3 \pm 0.3$ \\
& & & & & \\
$\mathrm{CuBr}$ & 0.02 & $22.5 \pm 0.1$ & $948 \pm 7$ & $0.70 \pm 0.02$ & $15.2 \pm 0.4$ \\
& & & & & \\
$\mathrm{CuBr}$ & 0.04 & $19.8 \pm 0.5$ & $896 \pm 16$ & $0.71 \pm 0.01$ & $12.6 \pm 0.7$ \\
& & & & \\
\hline
\end{tabular}




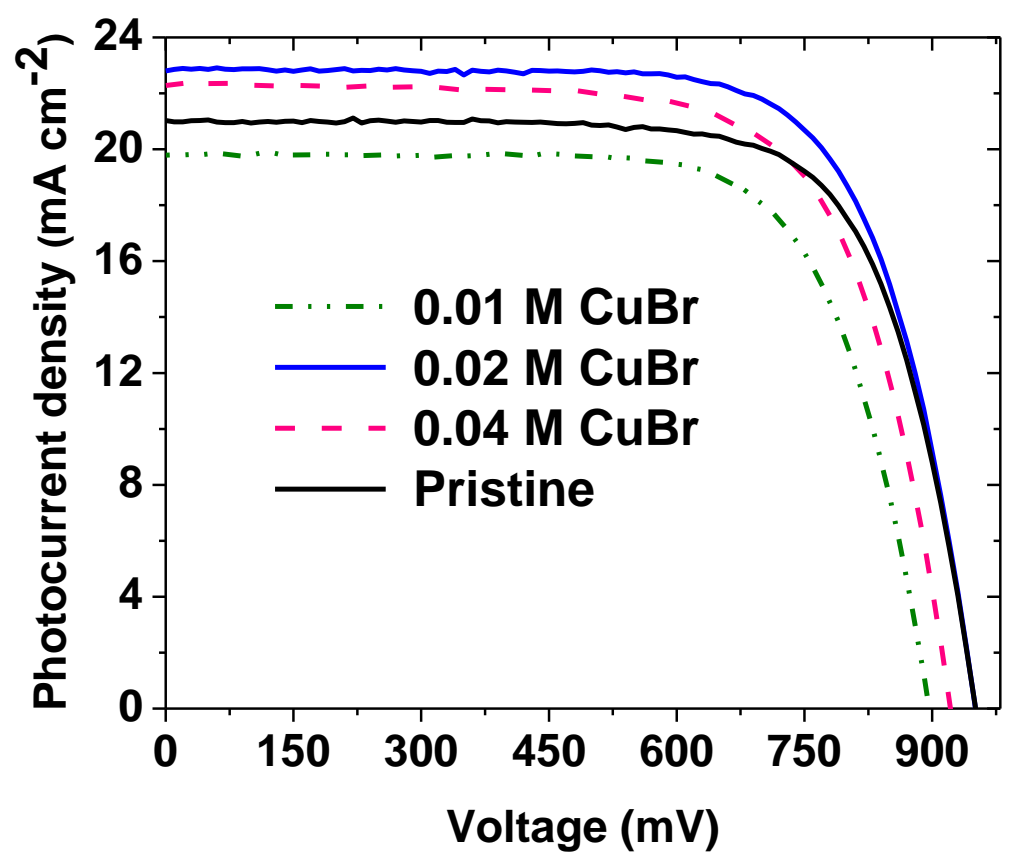

Figure S6. Current-voltage characteristics of devices under illumination of $100 \mathrm{~mW} \mathrm{~cm}{ }^{-2}$ obtained with varying concentration of $\mathrm{CuBr}$ additive. 


\section{WILEY-VCH}

Table S3. Summary of the photovoltaic parameters derived from J-V measurements for the pristine and additive-based perovskite solar cells (batch of 30 devices) fabricated using twostep deposition method.

\begin{tabular}{|c|c|c|c|c|}
\hline Type of Sample & 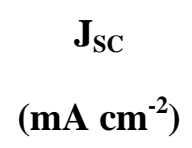 & $\begin{array}{c}\mathrm{V}_{\mathrm{OC}} \\
(\mathrm{mV})\end{array}$ & FF & $\begin{array}{l}\text { PCE } \\
(\%)\end{array}$ \\
\hline Pristine & $20.7 \pm 0.4$ & $945 \pm 13$ & $0.69 \pm 0.02$ & $13.7 \pm 0.3$ \\
\hline AgI & $19.1 \pm 0.1$ & $1007 \pm 11$ & $0.71 \pm 0.01$ & $14.0 \pm 0.2$ \\
\hline NaI & $22.6 \pm 0.2$ & $900 \pm 9$ & $0.72 \pm 0.02$ & $14.7 \pm 0.5$ \\
\hline CuI & $21.5 \pm 0.4$ & $982 \pm 14$ & $0.70 \pm 0.01$ & $15.0 \pm 0.2$ \\
\hline $\mathrm{CuBr}$ & $22.5 \pm 0.1$ & $948 \pm 7$ & $0.70 \pm 0.02$ & $15.2 \pm 0.4$ \\
\hline
\end{tabular}




\section{WILEY-VCH}

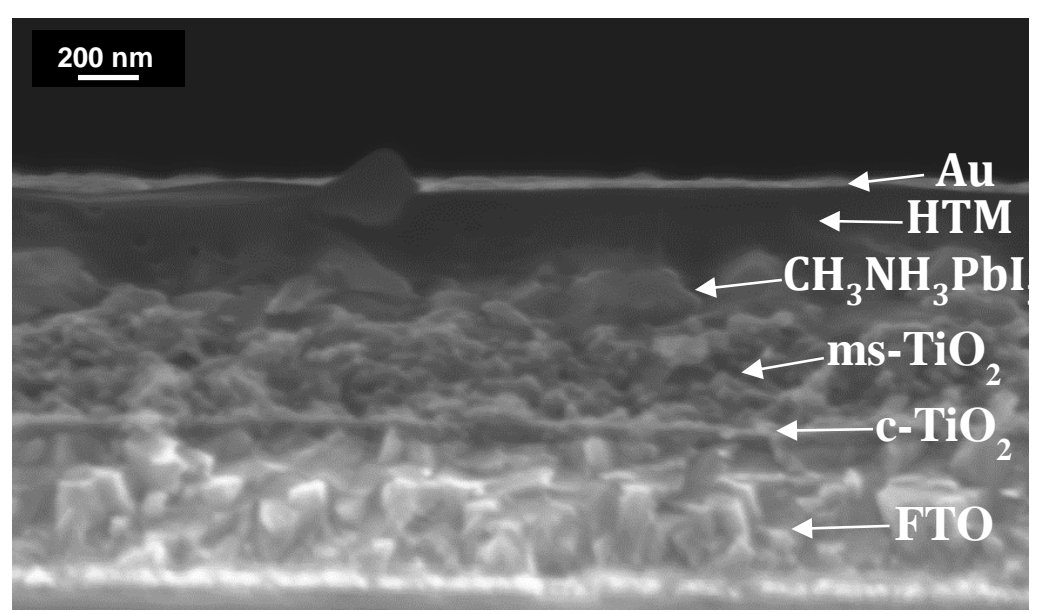

Figure S7. SEM cross sectional micrograph of a complete device having the structure of: FTO/compact $\mathrm{TiO}_{2} /$ mesoporous $\mathrm{TiO}_{2} / \mathrm{CH}_{3} \mathrm{NH}_{3} \mathrm{PbI}_{3} /$ Spiro-MeOTAD/Au. 


\section{WILEY-VCH}

Table S4: Summary of the thickness values for perovskite caping layers on top of mesoporous $\mathrm{TiO}_{2}$ (measured using a Veeco Dektak 150 profilometer) and FWHM values obtained from the corrsponding lead halide XRD patterns.

\begin{tabular}{|c|c|c|}
\hline Type of Sample & Thickness (nm) & FWHM (20) of (001) PbI $_{2}$ peak \\
\hline Pristine & $150 \pm 20 \mathrm{~nm}$ & 0.0487 \\
\hline CuBr & $170 \pm 30 \mathrm{~nm}$ & 0.0325 \\
\hline CuI & $160 \pm 20 \mathrm{~nm}$ & 0.0372 \\
\hline NaI & $130 \pm 20 \mathrm{~nm}$ & 0.1467 \\
\hline AgI & $190 \pm 30 \mathrm{~nm}$ & 0.0412 \\
\hline
\end{tabular}




\section{WILEY-VCH}
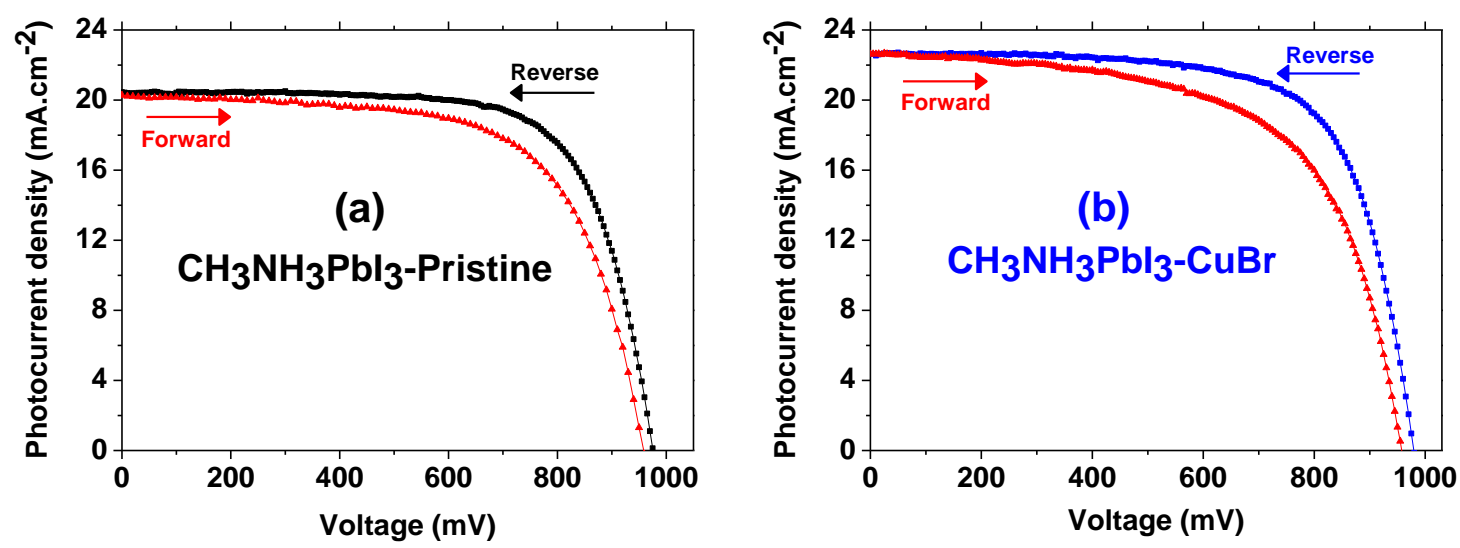

Figure S8. J-V curves for devices fabricated from (a) pristine and (b) $\mathrm{CuBr}$ based perovskite measured by forward (short circuit $\rightarrow$ open circuit) and reverse (open circuit $\rightarrow$ short circuit) scans with $10 \mathrm{mV}$ voltage steps and $40 \mathrm{~ms}$ delay times under AM $1.5 \mathrm{G}$ illumination. 


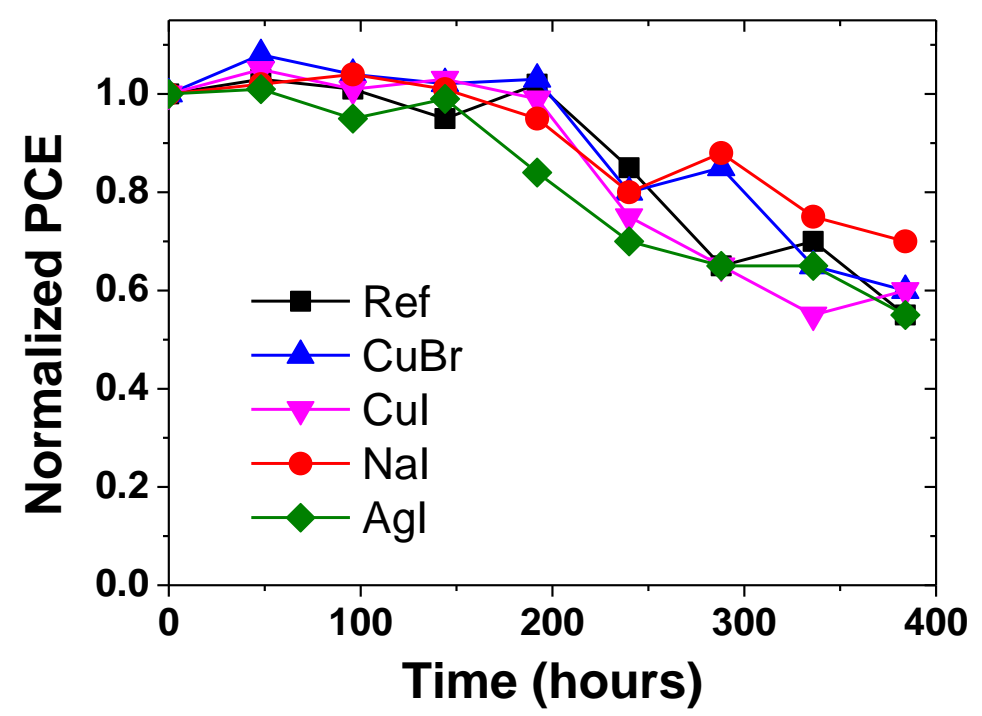

Figure S9. The average value of power conversion efficiency (Normalized PCE) as a function of time for the freshly prepared solar cells is used as the normalization reference value (i.e. for the five types of samples, their initial PCE values are all normalized to 1 ). The $\mathrm{J}-\mathrm{V}$ scans were measured under simulated air mass 1.5 global (AM1.5G) solar irradiation. The devices were stored under ambient conditions. 

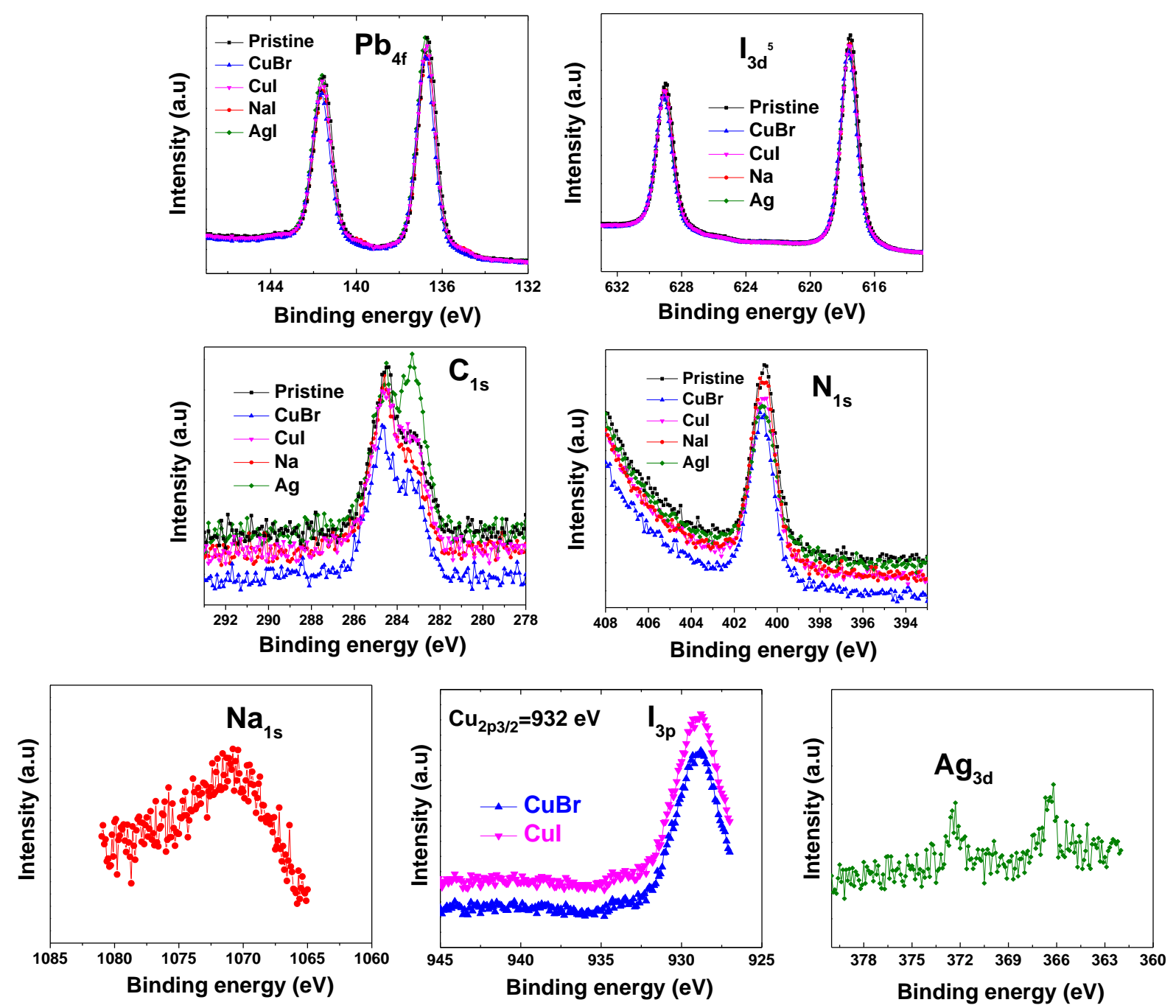

Figure S10. X-ray photoelectron spectroscopic (XPS) analysis of pristine, CuBr-, CuI-, NaIand AgI-based perovskite films. 